\title{
ACERCA DEL TOPÓNIMO PATAGONIA, UNA NUEVA HIPÓTESIS DE SU GÉNESIS
}

Magallanes y El término PATAGÓN*

Sabemos que fue Fernando de Magallanes quien denominó pueblos patagones a los aborígenes que encontró por la bahía de San Julián ${ }^{1}$ en el año 1520; esto nos lo hace saber su cronista y compañero de viaje Antonio Pigafetta. De los cuatro manuscritos de este cronista conocidos en la actualidad ${ }^{2}$, utilizaremos para el presente trabajo el existente en la Biblioteca Ambrossiana ${ }^{3}$, allí se puede leer: "Il capitano generale nomino questi po-

* Agradecimientos: a la doctora Temperley por sus comentarios en lo referente a novelas de caballerías y crítica textual, al licenciado Cavallero por sus observaciones y traducciones del griego, al licenciado Alex Vallega por su apoyo y a Katy Kostelac (mi mujer) por su paciencia.

${ }^{1}$ La bahía de San Julián se encuentra en República Argentina, aproximadamente a 49 grados de latitud sur.

2 "Nous connaissons à présent quatre manuscrits du récit de Pigafetta: trois en français, un en italien. Tous appartiennent à la première moité du $\mathrm{XVI}^{\mathrm{e}}$ siècle. Le texte italien se trouve à la bibliothèque Ambrosienne, à Milan (ms. Ambrosiano L.103 Sup.). Deux des manuscrits français sont conservés à la Bibliothèque Nationale à Paris: mss. français 5650 et 24.224. Le troisième appartient à la collection de T. Fitzroy Fenwick, à Cheltenham, Thirlestaine House [actualmente este último manuscrito se encuentra en la Biblioteca de la Universidad de Yale]" (J[EAn] DenucÉ, Pigafetta relation du premier voyage autour du monde par Magellan. 1519-1522. Edition du texte français d'apres les manuscrits de Paris et Cheltenham, Imprimerie Gust Janssens, Anvers, 1923, p. 9).

${ }_{3}$ Notizie del Mondo nuovo con le figure[s] de paesi scoperti descritte da Ant. ${ }^{o}$ Pigafeta vicentino cavaglieri d Rodi, ms. L.103 Sup. Según Denucé es el más completo, conciso (op. cit., p. 16) y antiguo, estima su escritura alrededor de 1525 (p. 14). De aquí en adelante cada vez que hagamos referencia a la crónica de Pigafetta la estaremos haciendo a este manuscrito (a no ser que se especifique lo contrario), el cual cotejamos con Antonio Pigafetta, Il primo viaggio intorno al mondo con il trattato della sfera, ed. Neri Pozza, Vicenza, 1994. 
puli patagoni" (f. 9v), observamos que se lee "populi patagoni", en plural. Debemos aclarar que también existen otros relatos de fuentes directas hechos por otros expedicionarios que participaron del viaje conjuntamente con Magallanes y también relatos de primera mano ${ }^{4}$ menos divulgados:

\section{Fuentes directas existentes}

Se encuentran el denominado "Diario de Albo" , la relación de "Ginés de Mafra"6, el "Roteiro da Piloto Genoves"7 y una "narratione de un portoghese" compañero de Duardo Barbosa ${ }^{8}$.

Escribiremos "Pigafetta" con doble "t" tal como se halla firmado en f. 92v, a pesar que en su título se lo encuentra con una sola " $t$ " (aclaramos que éste se lo ubica en una primer página que actúa como carátula y se puede ver claramente que no pertenece al corpus de la crónica). A lo largo del presente trabajo mantendremos las mayúsculas, minúsculas, palabras aglutinadas, $\mathrm{u}$, $\mathrm{v}$, f, la falta de acentos y numeración romana como y donde se hallen expresadas según nuestras fuentes, desarrollaremos las abreviaturas y la ese larga como s; en caso de existir capítulos o folios mal numerados colocaremos la correcta numeración entre corchetes y, por último, los resaltados en frases textuales se encuentran en el original salvo que se exprese lo contrario.

${ }^{4}$ Escritos realizados por terceros de acuerdo con declaraciones tomadas a navegantes de la expedición.

5 Martín Fernández de Navarrete, Colección de los viages y descubrimientos, que hicieron por mar los españoles, desde fines del siglo XV, Expediciones al Maluco. = Viage de Magallanes y de Elcano, Imprenta Nacional, Madrid, 1837, t. 4, pp. 209-247.

6 Antonio Blázquez y Delgado Aguilera, Descripción de los reinos, costas, puertos e islas que hay desde el Cabo de Buena Esperanza hasta los Leyquios por FERNANDO DE MAGALLANES piloto portugués que lo vió y anduvo todo, Libro que trata del descubrimiento y principio del estrecho que se llama de Magallanes por GINÉS DE MAFRA que se halló en todo y lo vió por vista de ojos y Descripción de parte del Japón (Anónima), Real Sociedad Geográfica, Madrid, 1920.

7 Según EnriQue de Gandía y Manuela Fernández Reyna (León Pancaldo y la Primera Expedición Genovesa al Río de la Plata. Estudios históricos, Ateneo Popular de la Boca, Buenos Aires, 1937) y Luigi Avonto (I compagni italiani di Magellano con un'appendice sul "Roteiro" di un pilota genovese, sotto gli auspici di Academia Nacional de Letras del Uruguay y Accademia Archeologica Italiana, El Galeón, Montevideo, 1992) este Piloto sería León Pancaldo. Otros autores opinan que posiblemente haya sido Juan Bautista de Poncerva (MARTIN Torodash, "Magellan historiography", The Hispanic American Historical Review, 51, 1971, p. 319).

8 Gio Battista Ramusio, Delle navegationi et viaggi, Primo volume, Stamperia de'Givnti, Venecia, 1554, pp. 408v-409r. Esta "narratione" podría haber sido hecha por Basco Gomes Gallego (TorodAsH, art. cit., p. 313). 
Fuentes directas que estarían perdidas

Posibles crónicas escritas por: Fernando de Magallanes ${ }^{9}$, Andrés de San Martín ${ }^{10}$, por Juan Serrano ${ }^{11}$, una narración de Martín de Loza o de Aimonte conocida como "Roteiro de la Torre do Tombo"12, un libro escrito según Barros por Gonzalo Gómez de Espinosa ${ }^{13}$, una posible relación de Sebastián Elcano ${ }^{14}$ y las cartas enviadas por él a Carlos $\mathrm{V}^{15}$.

9 Antonio de León Pinelo en su catálogo cita: "FERnANDO DE MAGALLANES, Efemérides, ò Diario de su Navegación, M. S. que estuvo en poder de Antonio Moreno, Cosmógrafo de la Casa de la Contratación, según Don Nicolàs Antonio" (Epitome de la Bibliotheca oriental, y occidental, náutica y geográfica, Carlos Sanz López, ed. facs. de la de 1738, Madrid, 1973, p. 667) y Andrea DA Mosto en su obra crítica expresa: "Il Giornale che, secondo alcuni, fu scritto da Magellano durante il viaggio, è perduto fino dal 1783" (Il primo viaggio intorno al globo di Antonio Pigafetta, Raccolta di documenti e studi pubblicati dalla R. Commissione Colombiana, Roma, parte V, vol. 3, 1894, p. 32).

10 Iô̂o BARros expresa: "onde estaua o astrologo An- / dres de San Martin: o qual registou / este mandado em hum liuro" (Da Asia de Ioâo de Barros: dos feitos queos portvgueses fezerâo no decobrimento $\mathcal{E}$ conquista dos mares $\mathcal{E}$ terras do Oriente, Impressa per Iorge Rodriguez, Decada Terceira, Livro Quinto, Lisboa, 1628, cap. 9, f. 143r) y más adelante: "entre os / quaes foi hum liuro feito per elle de toda aquella sua viagem" (cap. 10, f. 146v). En las declaraciones realizadas en Valladolid por Gines de Mafra en el año 1527, transcriptas por FERnÁndez de NAVARRETE, se puede leer: "los cuales libros de rotea, y otros dos que había hecho Andrés de San Martín, piloto de S.M." (op. cit., p. 387).

11 Angela de Poli, Ricerche su Antonio Pigafetta, en Nuovo Archivio Veneto, 38 (luglio-dicembre, 1919), p. 82; EnRIQue Ruiz Guiñazú, Proas de España en el mar Magallánico, Peuser, Buenos Aires, 1945, p. 53.

12 Torodash, op. cit., p. 320; Ruiz Guiñazú, op. cit., p. 54.

13 "\& assi Gonzalo Gomez de / Espinosa, o capitano... Do qual eu ouue / alguns papéis que lhe achei, entre os / quaes foi hum liuro feito per elle de toda aquella sua viagem" (BARros, op. cit., cap. 10, f. 146v).

${ }^{14}$ La existencia de esta relación nos la ha trasmitido Oviedo y VALdEz: "yo he seguido la re / lación que Juan Sebastián del cano me dio" (Libro XX Dela segunda parte dela general historia delas Indias. Escripta por el Capitán Gonçalo Fernández de Oviedo, y Valdez. Alcayde dela fortaleza, y puerto de Sâcto Domingo, E la isla Española. Cronista de fu Magestad. Que trata del estrecho de Magallans. Por Francisco Fernández de Cordova, Impressor de su Magestad, Valladolid, 1557, f. 9v). Al respecto, Angela de Poli, op. cit., p. 137, observaba que ningún otro escritor había comentado de la existencia de la relación de Elcano hasta ese momento: "Che il Del Cano abbia scritto una, sia breve, relazione, parrebbe dall'Oviedo, che dice di averla consultata, mentre nessun altro scrittore ne parla".

15 Torodash, op. cit., p. 321. 
Fuentes de primera mano

La carta escrita por el secretario de Carlos V, Maximiliano Transilvano $^{16}$, dirigida a "allo illustrisimo \& reverendisimo Signore, il Signore Cardinal Salzburgense" 17 con declaraciones recopiladas en 1522 al "Capitano della naue [Sebastián Elcano], \& da ciasun di quelli marinari, che son ritornati" (p. 383v), las declaraciones que el Alcalde Leguizamó tomó a "Joan de Sebastián Delcano, capitan, é á Francisco Albo, é Fernando de Bustamante"18, "la carta del contador Juan López de Recalde al Obispo de Burgos dándole cuenta de la llegada al puerto de las Muelas de la nao S.Antonio ${ }^{19}$..." dando noticia de "los dichos de todos los que en la dicha nao vienen" ${ }^{20}$, la carta de Antonio Brito dirigida al rey de Portugal haciéndole saber de la captura de algunos miembros de la expedición y de las declaraciones tomadas “á capitan [Gonzalo Gómez] y Maestre” (pp. 305-311), las declaraciones que pudo recopilar Pedro Mártir de Anglería ${ }^{21}$ de los pocos sobrevivientes de la nave "Victoria" y escribirlo entre los años 1522 y $1523^{22}$ e incluirlo en su Décadas del Nuevo Mundo. Por último hay cinco cartas escritas por Jacob Banièevic, secretario de Carlos V para el año 1519, dirigidas al Gobierno de la República de Ragusa (actual Croacia) dando noticia de la llegada de esta expedición y de algunas de las riquezas por ellos encontradas ${ }^{23}$.

\section{Fuentes de primera mano que estarían perdidas}

Según Ramusio, Anglería habría escrito una crónica específica sobre esta expedición: "Questo viaggio fu scritto molto partico-

16 Maximiliano de Transilvania.

17 Ramusio, op. cit., pp. 383v-389v.

18 Navarrete, op. cit., pp. 285-295.

19 Esta nave desertó de la expedición en la zona del estrecho de Magallanes.

${ }^{20}$ Navarrete, op. cit., pp. 201-208.

21 Pedro Mártir de Anglería, Décadas del nuevo mundo [1530], Edit. Bajel, Buenos Aires, 1944.

${ }^{22}$ La primera edición de las Décadas de Anglería fue impresa en el año 1530 y titulada De Orbe Nouo. Sin embargo, la dedicatoria de la Década Vy el capítulo VII, titulado "De la vuelta al mundo" (p. 425), ambos están dedicados al Papa Adriano VI, que fue Papa durante los años 1522 y 1523, es decir, ni bien arribada la nave "Victoria" a Sevilla, lo cual ocurrió según RAmusio el "sette di Settembre" de 1522 (op. cit., p. 383a).

${ }^{23}$ Stoyan Gavrilovic, "Documents in the Archives of Ragusa on Magellan's voyage”, The Hispanic American Historical Review, 45 (1965), pp. 595-608. 
larmente per Don Pietro Martire... ma hauendola mandata a stampare a Roma nel miserabil sacco di quella citta si smarri ${ }^{24}$, et per anchora non si sa oue si sia" (p. 382v).

De todos estos escritos, de fuentes directas, la crónica de Pigafetta es la única que denomina patagones a los aborígenes hallados por la bahía de San Julián. De primera mano sólo aparecen en las Décadas de Mártir de Anglería: "Vieron allí chozas de indígenas; pero es gente inculta, sin armas, que sólo se cubre con pieles; errante, sin asiento fijo, sin ley, de alta estatura: se llaman patagones" ${ }^{25}$ y en las declaraciones realizadas por Elcano y Albo ante el Alcalde Leguizamó como veremos inmediatamente.

\section{EL TÉRMINO PATAGÓN Y EL TOPÓNIMO PATAGONIA}

Por primera vez aparece el topónimo Patagonia cuando Magallanes, frente a una situación de rebelión de algunos de sus compañeros, manda abandonar a Gaspar de Casado y a un sacerdote $^{26}$ "in questa tera patagonia" 27 , es decir "en esta tierra patagonia". Aparece nuevamente tres folios más adelante cuando Pigafetta nos aclara: "Chiamassemo aquesto streto el streto patagonicho" " 28 y por último está incluido en un mapa donde se puede leer: "Regione patagonia" y "Streto patagonico" (f. 14v). Con respecto a este topónimo, como bien lo señala González, es de extrañar cómo María Rosa Lida de Malkiel haya ex1527.

${ }^{24}$ Esto corresponde a los saqueos y robos ocurridos en Roma en el año

25 Op. cit., p. 428. Ramón Morales al respecto expresa: "Al parecer entiende que patagón es el nombre que los aborígenes se daban a sí mismos”, "Patagones y patagonia: un caso de denominación epónima con una errónea atribución geográfica”, Anales del Instituto de la Patagonia, Punta Arenas, Chile, 19 (1989-1990), p. 30.

${ }^{26}$ Para Ramusio (op. cit., 391d) este sacerdote sería Giovanni de Cartagena.

27 Pigafetta, op. cit., f. $9 v$.

28 Ibid., f. 12v. Observamos que está escrito "patagonicho" con la "ch" con grafía de la época y así lo ha transcrito Mosto (op. cit., p. 63). Otros autores han transcrito "patagonico", como AмоReтti (Primo viaggio intorno al globo terracqueo ossia ragguaglio della navigazione alle indie orientali per la via d'occidente fatta dal cavaliere Antonio Pigafetta patrizio vicentino, publicado por Carlo Amoretti, Stamperia di Giuseppe Galeazzi, Milano, 1800, p. 40), CAMILlo Manfroni (Il primo viaggio intorno al mondo di Antonio Pigafetta, Milano, 1956, p. 56) y Pozzi (op. cit., p. 122). 
presado que "hubo que esperar hasta que en el siglo XviII se agregara el sufijo de lugar -ia y quedara creado el topónimo Patagonia"29, "cuando con sólo observar el mapa antedicho, queda a la vista este topónimo"30.

No hemos encontrado ningún autor que haga referencia a la existencia de este topónimo en el cuerpo de la crónica, todos hacen referencia al existente en el mapa, quizás por no haber contado con el original o ediciones críticas. Quizás sea ésta la razón por la cual la profesora Battini erróneamente afirma: "sin el mapa de Pigafetta nuestro topónimo Patagonia se hubiera perdido" 31 .

Observamos que Francisco Albo y Juan Sebastián Elcano, al referirse al pasaje donde son abandonados el sacerdote y el navegante, se expresan diferente: "porque se querían tornar á alzar otra vez, é los echó en tierra de los patagones" 32 y "echó al dicho Joan de Cartagena é á un clérigo en tierra de los patagones" (p. 287). Confirmando esta expresión, en la edición de Amoretti se puede leer: "e abbandonollo nella terra de' Patagoni con un prete suo complice" (p. 33). No es lo mismo "tera patagonia", como dice el manuscrito y así lo transcriben en sus ediciones críticas Mosto (p. 59) y Pozzi (p. 119), que "terra de' Patagoni" o "tierra de los patagones".

Con referencia al nombre que se le da al estrecho, pensamos que es de suma importancia hacer notar que Magallanes lo llamó como hemos visto: "el streto patagonicho" (f. 12v). Este era el estrecho que tanto buscaba, de importancia vital para el éxito de toda la expedición, y en lugar de llamarlo, por ejemplo, "de la Virgen María" o "del Espíritu Santo", lo llama "patagonico" (o "patagonicho" que es lo mismo), lo que denota la relevancia que había tenido para Magallanes el encuentro con estos patagones, hecho hasta ahora no observado por ninguno de los autores consultados.

29 María Rosa Lida de Malkiel, "Fantasía y realidad en la conquista de América", en Homenaje al Instituto de Filología y Literatura hispánicas "Dr. Amado Alonso" en su cincuentenario, 1923-1973, Buenos Aires, 1975, p. 220.

30 Javier Roberto González, Patagonia-Patagones: orígenes novelescos del nombre, Subsecretaría de Cultura, Provincia del Chubut, 1999, p. 5.

31 Berta Elena Vidal de Battini, "Patagonia nombre de una región Argentina”, BAAL, 40 (1975), núms. 155/156, p. 147.

32 Navarkete, op. cit., p. 291. 


\section{EL TÉRMINO PATAGÓN Y LAS GRANDES HUELLAS}

Es importante recordar que en ningún momento Pigafetta relaciona el término patagón con el tamaño de los pies o de las huellas dejadas por ellos, ya sea por sus pies desnudos o cubiertos por gruesas pieles. Con respecto a esto último, Pigafetta sí nos hace saber que llevaban sus pies cubiertos con pieles: "haveva ali / piedi albarghe de le medesme pelle ${ }^{33}$ che copreno li piedi a uzo di scarpe" 34 pero con dos folios de anterioridad a ser nombrados como populi patagoni, es decir, sin ningún tipo de relación entre el hecho de usar albargue y esta denominación. Pastell, en su obra El descubrimiento del Estrecho de Magalla$n^{3}{ }^{35}$, sin ningún tipo de asidero afirma: "Por la grande huella de sus pies llamólos Magallanes patagones" y luego aclara: "Algunos niegan esta etimología asegurada por Pigafeta”, lo cual, como hemos visto, es totalmente erróneo.

La primera vez que se hace referencia a las grandes huellas es durante la segunda expedición que se acercó por esta zona, al mando del capitán general fray García Jofre de Loaiza en el año 1526, es decir, cinco años más tarde que la expedición de Magallanes.

Fernández de Oviedo, en su edición de 1557, lo expresa de la siguiente manera: "pero vieron traça y / vestigios y rastro de grandes pisadas / de gigantes o patagones de los que se a / dicho"36. Aquí se entiende que esta "traça", "vestigios", y "rastro de pisadas" fueron hechas por "gigantes" 37 , a quienes, como se

33 Corresponde a la piel del guanaco (Lama guanicoe).

34 Op. cit., f. 7v. Con referencia a esta cita, Arriba confunde a Amoretti con Ambrosetti (Juan Bautista Ambrosetti, antropólogo y etnógrafo) al expresar: "En su edición Ambrosetti anota que el nombre se origina en el calzado de piel de guanaco de los nativos que les daba a los pies apariencia de patas de oso" (María Laura de Arriba, "Los sonidos de la enunciación en la primera vuelta al mundo", $R C L L, 2004$, núm. 60, p. 65). Se entiende claramente la confusión al observar la similitud entre "Amoretti", "Ambrossiano" (Biblioteca Ambrossiana) y "Ambrosetti".

35 Pablo Pastells, El descubrimiento del Estrecho de Magallanes en conmemoración del IV centenario, con colaboración del Rvdo. Constantino Bayle, Parte primera, Sucesores de Rivadeneyra, Madrid, 1920, p. 67.

36 Libro XX Dela segunda parte dela general historia delas Indias. Escripta por el Capitán Gonçalo Fernández de Oviedo, y Valdez. Alcayde..., cap. 8 [9], f. xxviiv. Nos extraña que tanto Morales como González no hagan referencia a este párrafo.

37 Debemos aclarar que no es de interés en el presente trabajo realizar algún tipo de análisis referente a la estatura agigantada o no de los patagones. 
ha dicho, también llaman "patagones", pero en ningún lugar se expresa algún tipo de relación entre las huellas y el nombre patagón, sólo dice que fueron hechas por ellos.

Luego de Loaiza, también comentaron la existencia de grandes huellas el soldado Montemayor, miembro de la expedición de Pedro Sarmiento de Gamboa en el año de 1580:

...y por camino de la gente que allí vive, donde hallaban huella de pies grandes como de aquellos indios, y de otros como los deste reino ${ }^{38}$;

Thomas Cavendish en su primera expedición del año 1586:

...for we followed them, and they ran from us as we had been the wildest things in the world. We tock the measure of one of their feet, and it was eighteen inches long ${ }^{39}$.

Aquí entendemos que hace referencia a la huella y no al pie explícitamente, y Antoine Knivet (miembro de la segunda expedición de Cavendish de 1592) afirma:

J'affirme que j'ai mesuré sur ce rivage la trace du pied d'un d'entr'eux, laquelle étoit quatre sois plus longue qu'une des nôtre ${ }^{40}$.

Marín Pina nos aclara que las

especulaciones sobre este aspecto [el tamaño de los pies] y las relaciones entre el nombre PATA-GÓN y la desmesura del pie, agrandado por las pieles que les servían de calzado puede deberse, a nuestro juicio, a un caso de etimología popular ${ }^{41}$.

38 M[andel] Serrano y Sanz, Historiadores de Indias, Bailly Baillière e Hijos Editores, Madrid, 1909, t. 2, p. 656.

39 An historical account of all the voyages round the world performed by English navigators, F. Newbery, London, 1774, t. 2, p. 170.

${ }^{40}$ Charles de Brosses, Histoire des navigations aux terres australes, Paris, 1756, t. 1, p. 232. González, seguramente desconociendo los dichos de Loaiza, Montemayor y Knivet en su primera expedición, expresa en su excelente trabajo que recién otro explorador "posterior en setenta y dos años a Magallanes, Thomas Cavendish... en 1592 [segunda expedición] dice haber medido una huella encontrada en la playa " (op. cit., p. 9).

41 María Carmen Marín Pina, Edición y estudio del ciclo español de los Palmerines, tesis doctoral, Universidad de Zaragoza, 1988, p. 253. 


\section{EL TÉRMINO PATAGÓN Y LOS GRANDES PIES}

La primera vez que aparece impresa la relación del término patagón con los grandes pies de estos aborígenes fue en el año 1552, cuando el cronista López de Gómara, refiriéndose a la expedición de Magallanes, afirmó: "que tienen disformes pies, por lo cual los llaman patagones" ". Aquí compartimos lo ya dicho por Battini: "Creo que disformes tiene aquí el sentido de muy grandes" (p. 152). Cinco años más tarde, en 1557, sale a luz el libro XX de la Segunda parte de la Historia general y natural de Indias de Fernández de Oviedo, aunque ésta fuera escrita en realidad casi diez años antes, en $1546^{43}$. Aquí aparecen los dichos de Aréizaga (miembro de la expedición de Loaiza), que Fernández de Oviedo recopiló en 1535: "quando le vi [Fernández de Oviedo] el año de mill y qui / nientos y treynta y cinco [1535]" (cap. 5, f. xxiiir): "que la vna costa / y la otra del estrecho / de Magallans, es habitada de Gigan / tes a los quales nuestros españo / les llamaron Patagones por sus / grandes pies" (cap. 13, f. xxxiiir). Battini nos hace saber que "nada de esto dice Aréizaga en la Relación oficial" (p. 151) publicada por Navarrete ${ }^{44}$. Nuevamente, al referirse a un hecho vivido por Aréizaga, Fernández de Oviedo expresa: "y quando quiso amanescer vieron / más de dos mill patagones o gigantes; / este nombre patagón fue a disparate [lo resaltado es nuestro], / puesto a esta gente por los christia / nos por que tienen grandes pies; pe / ro no desproporcionados según la al / tura de sus personas pero muy gran / des masque los nuestros" ${ }^{\text {" }}$.

42 Francisco López de Gómara, Historia general de las Indias, EspasaCalpe, Madrid, 1932, t. 1, p. 218.

43 "En este primero libro (ques veynte deste / segundo volumen o parte) se tracta del fomoso estrecho de Magallans, y de lo / que del al presente se sabe hasta este año de M.D.xlvi. [1546] años" (op. cit., f. iiiiv).

44 Op. cit., t. 5, pp. 223-225.

45 Op. cit., cap. 6, ff. xxiiii $v-\mathrm{xxv} r$. EnRIQue Pato, en sus conclusiones, cita este párrafo y dice: "No es extraño, pues, que J. de Aréizaga [lo] escribiera en Religiosos en el Nuevo Mundo" (De nuevo sobre el origen de patagones > patagonia, www.monografias.com/ trabajos16/ patagones/ patagones. shtml, 2003, consultado 1 septiembre de 2006). Creemos que no existe ningún trabajo de Aréizaga titulado "Religiosos en el Nuevo Mundo", como Pato afirma, y que ha consultado, como nosotros, el sitio de internet de la Universidad de Brigham Young: www.corpusdelespanol. org/x4mi. asp? $\mathrm{n}=3$ donde sí aparece Aréizaga como autor de este trabajo: "TÍTULO: Religiosos en el Nuevo Mundo. Siglos xvi y xvir. AUTOR: Aréizaga, Juan de FECHA: [_- ] VER FUENTE ORIGINAL". Consultamos la "VER FUENTE ORIGINAL" 
Nos preguntamos: ¿no habrá sido Juan de Aréizaga el mentor de esta relación con los pies grandes, ya que, como acabamos de ver, Fernández de Oviedo lo trata de disparate? Creemos que es probable que Aréizaga haya utilizado esta expresión en forma personal, ya de regreso a España, al relatar su historia a los diferentes cronistas, desconociendo la razón por la cual Magallanes así los llamara.

Por otro lado, hacemos notar que Fernández de Navarrete incluye el siguiente comentario al detallar el viaje de Magallanes: "Los castellanos les llamaron Patagones por tener disformes pies, aunque no desproporcionados a su estatura", inmediatamente en nota número 6 de pie de página hace referencia a [Fernández de] Oviedo en "2da. part., lib. 20, cap. 6, f. 24v. y 25 ” (t. 4, p. 39), pero como citamos anteriormente, allí dice precisamente lo contrario:

...este nombre patagon fue a disparate [lo resaltado es nuestro] puesto a esta gente por los christianos por que tienen grandes pies; pero no desproporcionados según la altura de sus personas.

También, como está dicho supra, este comentario no corresponde, como Fernández de Navarrete afirma, al viaje de Magallanes, sino al de Loaiza, hecho hasta ahora no observado.

\section{PATAGÓN NO SIGNIFICA “DE PIE GRANDE”}

Etimológicamente, patagón no significa pie grande. "Atendiéndonos a que su estructura dispone dividirlo en 'pata' y 'gon"” (Morales, p. 62). Morales analiza su posible origen en las lenguas portuguesa, castellana e italiana:

allí citada y nos direccionó a la Biblioteca Virtual Cervantes, dándonos un error. En este sitio nos comunicaron que "ya no contamos con esa obra en nuestro catálogo, tuvimos que retirarla por motivos de edición" y que "los datos de la colección a la que pertenecía esa obra corresponden a: Historia real y fantástica del Nuevo Mundo. Edición: Caracas, Biblioteca Ayacucho, 1992". Consultamos esta obra y allí se transcribe, textualmente, parte de la obra de Oviedo con el título: "Los gigantes patagones", pero bajo la autoría errónea de Juan de Aréizaga (Historia real y fantástica del Nuevo Mundo, sel., pról., notas y bibliografía Horacio Jorge Becco, Biblioteca Ayacucho, Caracas, 1992, pp. 386-390); razón por la cual pensamos que Pato adjudicó erróneamente la autoría a Aréizaga. 
En portugués 'pata' se ha conocido como 'pate', 'perna' y 'pe’; 'gon' y 'go' nunca han existido. Invirtiendo la transcripción de la segunda parte de la palabra, consignamos que 'grande' o 'gran' han tenido su similar en los términos lusitanos 'grande', 'comprimido' y 'crescido’. Ninguno de estos tres últimos forma con alguno de los tres primeros la palabra buscada. En el castellano de la época, como en la actualidad, 'pata' designa la extremidad de un mueble o un animal; pero 'gon' o 'go' nunca han existido; y los términos 'grande' y 'gran' no eran distintos a como los conocemos en la actualidad. En idioma italiano el resultado es igualmente negativo, porque 'pata' no existe y para 'pie' se han conocido los términos 'zampa', 'piede', 'gamba', 'sopatrasca' y 'pianta'; 'gon' o 'go' tampoco han existido y 'grande' se designa simplemente como 'gran' (p. 14).

Con respecto al latín, como lengua madre de estas tres lenguas antedichas, expresa:

se hallan los términos 'patagiatus', 'patagium’ y ‘patagus'. Forcellini en su Lexican Totius Latinitatis (1833), sostiene que el primero es un adjetivo relacionado con el adorno de un vestido femenino; el segundo es una pieza de ropa femenina; y el último una enfermedad grave mortal. Es obvia también aquí la total desvinculación con la etimología antropométrica que nos ocupa (pp. 14-15).

González, incluyendo la lengua veneciana (ya que Pigafetta era de la región del Véneto), confirma lo expresado por Morales al decir que "ninguna de las cuatro admite la gramática la formación [sic] de un aumentativo mediante la adición de un sufijo *-agón a un sustantivo de base pata/pat-" (p. 8). Bataillon nos aclara:

...la sinonimia aparente de ‘pataco’ y ‘patagón’ con el castellano 'patán' y el portugués 'patego' no obliga de ninguna manera a pensar que algunas de estas cuatro palabras hacen especial referencia a 'disformes pies' o a 'grandes pies' ${ }^{46}$.

Groussac observa que se puede leer en el Diccionario de la Academia [Real Academia Española], "en sa premiere édition: 'Patagón. Lo mismo que patón'"47. Al respecto de esta definición, Battini observa este "lamentable error" y expresa:

${ }^{46}$ Marcel Bataillon, "Acerca de los patagones retractatio", Filología, 8 (1962), p. 36.

47 Paul Groussac, "Toponymie historique des côtes de la Patagonie", 
Aunque patagón no significó nunca patón en español, ya olvidado su verdadero origen, el ejemplo explicativo dado por la Academia se hizo clásico, y se repitió en todos los diccionarios y obras de investigación que tratan de nuestros indígenas y del nombre que les dio Magallanes, hasta nuestros días (p. 154).

\section{Groussac se pregunta:}

...pourquoi forger ce barbarisme de "patagones", alors qu'on avait "patones", plus bref, plus clair, tout à fait analogue aux sobriquets de "frentones", "orejones", etc., que les Espagnols ou les Portugais appliquèrent à d'autres tribus américaines? (p. 415).

\section{Lida de Malkiel nos aclara:}

patagón en el sentido de "pie grande" o de "patudo" no existe ni ha existido jamás en español ni en portugués ${ }^{48}$.

\section{DifERENTES SIGNIFICADOS DEL TÉRMINO PATAGONIA} A LO LARGO DEL TIEMPO

Se han esgrimido diferentes etimologías y significados de este término, aparte de los ya vistos relacionados con los pies o las huellas de los patagones: "En orden cronológico pertenece la primicia a" ${ }^{49}$ Vicente Fidel López, quien en 1869, relacionaba el topónimo Patagonia con la lengua quichua de la siguiente forma:

Ese nombre mismo de las Pampas y el de Patagonia son denominaciones que los Españoles recibieron de las colonias Quichuas que lindaban y amenazaban ya con la invasión de esos desiertos cuando las paralizó la conquista española. Son nombres que no tienen afinidad ninguna con las lenguas europeas, ni con la

Anales de la Biblioteca, Buenos Aires, 1912, p. 412. Entendemos que esta cita corresponde a la primera edición, publicada entre los años 1726 y 1739, ya que algunas líneas más adelante, Groussac aclara "cette premiere edition du Diccionario, dite «de autoridades»", que es como "el vulgo suele referirse a esta obra" (http://filosofia.org/enc/aca/aca.htm).

48 María Rosa Lida de Malkiel, "Para la toponimia Argentina: Patagonia”, HR, 20 (1952), p. 322.

49 José Imbelloni, La segunda esfinge indiana, antiguos y nuevos aspectos del problema de los orígenes americanos, Hachette, Buenos Aires, 1956, p. 349. 
lenguas australes de las tribus de nuestros desiertos... 'Pata' significa 'colina', collado; y 'cuna' ó más bien 'gunya', es la partícula disfija característica de los plurales quichuas: patagunya significa 'las colinas' ó más bien los 'campos ondulados'. Cualquiera que conozca los accidentes de aquellos terrenos dirá si están ó nó admirablemente bien caracterizados con el nombre ${ }^{50}$;

inmediatamente se pregunta: “¿Eran ó nó los Quichuas los que lo dieron? [el nombre patagonia]” (p. 523); esta pregunta, en el discurrir del texto, se entiende que tiene un sentido afirmativo.

Spegazzini, en una conferencia pronunciada en 1884 en la Sociedad Científica Argentina y publicada en sus Anales $^{51}$ ha expresado:

Los números en Patagón son, los 10 primeros propios de esta lengua, los de cien para arriba pertenecen á los 'Quichuas'. Entonces este pueblo tuvo relación con los Quichuas, y más, fácilmente estaban bajo el dominio de éstos; entonces los Incas á cada tribu imponían el deber de dar cien hombres de armas, ó los patagones habían sido divididos en tantos grupos de cien familias; eran entonces centurias, como los pueblos del Norte de Europa bajo el dominio de los romanos. En quíchua cien es 'patak', los patagones tienen nombre 'Aóniken';' 'pátak-aóniken' ó ‘centuria de aóniken ${ }^{52}$.

Al respecto Samitier opina: "inspirado más por la historia romana que por el pasado tehuelche" ${ }^{53}$ y Lida de Malkiel observa:

...lo que no es verosímil es que un término quechua o híbrido de quechua y tehuelche haya venido a designar a los tehuelches (p. 321).

Mariano Felipe Paz Soldán, en 1885, en su Diccionario geográfico estadístico expone algo muy parecido a lo dicho por López:

50 Vicente Fidel López, "Geografía histórica del territorio argentino", La Revista de Buenos Aires, 1869, t. 20, año 7, p. 523.

${ }^{51}$ Morales, op. cit., p. 15, seguramente por error de su fuente, expresa que fue pronunciada en el Instituto Geográfico Argentino en el año 1882.

52 Carlos Spegazzini, "Costumbres de los patagones", Anales de la Sociedad Científica Argentina, Buenos Aires, 17 (1884), p. 222.

53 Manuel Llarás Samitier, “PPor qué el nombre de Patagonia?", Revista Patagónica, 1984, núm. 16, p. 31. 
...en mi opinión, conforme con la de otros, la palabra 'Patagonia' es corrupción de la Quechua 'pata cuna', que significa: 'pata', cerros no altos; 'cuna', partícula del plural; es decir, muchos cerros no altos ${ }^{54}$.

En 1899 Markham (para entonces presidente de la Royal Geographical Society) afirmó que la idea de "tierra de terrazas" bien se ajustaba a la descripción dada por Charles Darwin de la Patagonia:

We knew, of course, from the descriptions of Charles Darwin, of that great tertiary plain and of its terraces, for I suppose it is now established that the word Patagonia is the same as the Quichua, 'Pata', 'a terrace', and 'cerna' ${ }^{55}$, the plural particle, meaning 'the land of terraces,' exactly as Charles Darwin has described them ${ }^{56}$.

\section{El filólogo Abeille también}

aseguró... que el vocablo Patagonia es de origen quichua. Tras explicar el resultado de sus investigaciones lingüísticas, terminó diciendo que dicha palabra quiere decir "país de las colinas'57.

En 1901, el coronel Manuel José Olascoaga publica su oposición al origen quichua:

También se pretende, por imposición incásica, el nombre Patagonia... Análoga violencia impone el empeño de hacer quichua la palabra traduciéndola 'colinas', 'mesetas' o 'gradas'58,

y presenta su hipótesis a través de la lengua pampa:

'Pa', la partícula que indica la idea de 'venir' y 'thagon', que significa quebrarse, romperse, despedazarse, podría sintetizarse en la frase 'Costa Brava' o algo parecido (p. 106).

54 Mariano Felipe Paz Soldán, Diccionario geográfico estadístico nacional argentino, ed. Felix Lajouane, Buenos Aires, 1885, p. 369.

${ }^{55}$ Seguramente hubo algún error tipográfico o de traducción y en lugar de "cuna” quedó expresado "cerna", error no observado por ninguno de los autores por nosotros consultados.

56 Clements Markham, "Explorations in Patagonia - Discussion”, The Geographical Journal, 14 (1899), núm. 4, p. 377.

57 Llarás Samitier, op. cit., p. 31.

58 Manuel José Olasconga, Topografía Andina-Aguas Perdidas, Biblioteca de la Junta de Estudios Históricos de Mendoza-Cabaut Eds., Buenos Aires, 1935 [1901], t. 1, pp. 105-106. 
En 1912, Paul Groussac, quien fuera director de la Biblioteca Nacional de la República Argentina,

había propuesto, apegado aún al dato de los calzados de piel de guanaco, la posibilidad de una expresión original portuguesa, entre expresiva y metafórica, 'pata de cão', 'pata de can', enseguida aglutinada y sincopada en 'patacão' y pluralizada, según los procedimientos de la gramática portuguesa, en 'patacões' de donde la versión italiana 'patagoni' de Pigafetta ${ }^{59}$.

El padre Pablo Pastell en 1920 retoma lo dicho por Olascoaga "añadiendo a la motivación puramente geológica de éste una consideración de índole sismológica" 60 y expresa que hay quienes

quieren derivar patagón de la lengua pampa, en la cual 'pa' indica la idea de venir, y 'thagón', la de quebrarse, romperse, despedazarse. Según esto, patagón significaría el que llega destrozado, y patagonia, tierra rota, despedazada por las violentas conmociones seísmicas ocurridas en remota antigüedad (p. 67).

"Más antojadiza e inverosímil", al decir de González, es la hipótesis expresada en 1939 por Julio Storni también a través de la voz quichua:

'Pata' = 'Poyo', o sea lugar elevado; Ribera, o sea orilla del mar (abarca estos conceptos el vocablo). 'Ko' = Agua. 'N' = Partícula usada, indica el lugar en donde se hace o suceden las cosas. 'I' = Luz, raíz fundamental. 'Au' = Espacio, tierra... Sería algo así como tierra de alturas, de mucha luz, con riberas sobre el mar. Ensayaré la misma voz en homenaje a las posibilidades, pero no a la realidad, suprimiendo la 'I', es decir eso de la luz, y así tenemos: 'Patakonau' y 'Patakoniau'(p. 10).

Bazán interpreta en 1941: "Patacumñia o Patagonia, 'la tierra del Pie o extremo que tiembla""61.

Deodat en una conferencia dada en 1953 en la Casa de Mendoza en Buenos Aires y publicada por La Casa de la Patagonia en 1955, afirma que:

${ }^{59}$ GonzÁlez, op. cit., p. 12.

${ }^{60}$ Ibid., p. 11.

61 Pedro BAzÁn, El país de Cón (Región andina) cumbre de la argentinidad, Buenos Aires, 1941, p. 302. 
La grafía de este nombre mantiene hasta hoy su pureza primitiva. $\mathrm{Su}$ forma física es paleográfica. Es en puridad e indiscutiblemente un italianismo... Del relator mencionado son estas palabras concurrentes: "El capitano generale (título con que se alude a Magallanes) nominó questi populi Patagoni”. De este gentilicio, de notoria cuna lusitana, deriva el adjetivo "Patagonicho", otro italianismo cronológicamente posterior creado para calificar al nuevo estrecho, según lo expresa el mismo testigo: "chiamassemo a questo streto el Streto Patagonicho", y lo enseña su mapa rudimentario. "Patagonia", entonces, como nombre aplicado a una determinada región de nuestro suelo actual, proviene, no de una realidad histórica, sino de una documentada verdad cartográfica $^{62}$.

Mas adelante, sin embargo, en el mismo trabajo, Deodat presenta otra hipótesis sobre este topónimo:

Tengo como presunción verosímil que el espectáculo de aquella gente sin residencia fija; dueña de cueros que les servían para improvisar sus habitaciones... Admito, pues, como probable, que Magallanes, para expresar sintéticamente y con justeza la opinión que le merecieron los autóctonos de costumbres tan primarias, haya necesitado el auxilio de un vocablo de su idioma nacional, pero dándole un sentido traslaticio, dijese: Patacoes, acordando pluralidad al sustantivo patacao. Si así fuera, Magallanes habría logrado conseguir un término cabal y definitivo de su pensamiento. En tiempos de Don Juan III (1521-1557) conocíase con ese nombre una moneda de cobre del valor de diez reis. En España llamaban patacón a otra igual del mismo metal, que valía dos cuartos u ocho maravedíes, o sea unos doce centavos de nuestra moneda. Conforme a esta hipótesis, el presunto gentilicio original

${ }^{62}$ Leoncio Santiago Deodat, Alrededor del topónimo Patagonia, separata del Suplemento del núm. 24 de Patagonia, Boletín de la Casa de la Patagonia, Buenos Aires, 1955, p. 14. EnriQue PATo al respecto de este "italianismo", cita erróneamente (op. cit., p. 4) como fuente una nota periodística publicada por Leoncio Santiago Deodat, "Noticias históricas de las guaridas galesas en Madryn", en semanario Golfo Nuevo, Puerto Madryn, 9 de julio de 1932. Esta nota hace referencia al primer grupo de inmigrantes galeses que llegaron a las costas patagónicas a mediados del siglo xIx y de las peripecias que tuvieron que sufrir hasta poder establecer la primera colonia. Al finalizar, Deodat expone el origen del topónimo "Madryn", pero en ningún momento analiza o nombra el topónimo "Patagonia" (agradecemos a la señora Celia A. Chacón, Directora de la Biblioteca Municipal D.F. Sarmiento, de Puerto Madryn, por su ayuda para validar esta información). 
Patacoes tendría este significado: 'gente o indios de escaso valer, un puñado de cobre vil amonedado' ${ }^{63}$.

Al respecto de su relación con el nombre de una moneda, ya en 1924 Lehmann Nitsche opinaba: "No está de más dejar constancia que nuestro término [patagón], nada tiene que ver con el nombre de una moneda bien conocida, el "patacón" 64 . Mucho más recientemente, González nos recuerda la existencia de una moneda denominada patagón que circuló desde el año $1579^{65}$ "en Flandes y en Luxemburgo" ${ }^{66}$.

Hasta aquí, para quienes quieran mayores detalles de estas diferentes etimologías y las refutaciones, le recomendamos el excelente trabajo hecho por González (pp. 10-16). Pero sigamos, Thomas Bridge, que vivió gran parte de su vida junto a los indios yamanas, en su Diccionario yamana-inglés desarrolla el siguiente significado:

patag-önia, p.-umöni, -umutu i.s. To be said of any broad thing or surface, hau ökan kö-p.-ö.-tagömi In my house there is lying a board. p.-umöci To fall in and spread abroad as a house weakly tied toghe-

63 Op. cit., p. 27. Al igual que Groussac, Deodat observa el término Patacoes, pero con significado diferente.

64 R. Lehmann Nitsche, "Bases para la toponimia indígena de la Patagonia", Boletín del Instituto de Investigaciones Históricas, Buenos Aires, 1924, núms. 17/18, p. 242. En este párrafo y en su entorno, cuando dice "una moneda bien conocida", no detalla cuándo era "bien conocida”, por eso pensamos que está haciendo referencia al "patacón” que circulaba para fines del siglo xix en la República Argentina y por eso aclara que "nada tiene que ver"; ya que las otras monedas que han sido llamadas también patacones, por ejemplo y como veremos inmediatamente, el patacao portugués o el patacón de Flandes no son monedas precisamente "bien conocidas".

${ }^{65}$ Observamos que otros autores también nombran a esta moneda como pataccon, asimismo, afirman que su circulación fue introducida en Flandes en 1612 (www.pierre-marteau.com/ wiki/ index.php?title=How_much_ Money_was_a_Pattacon\%3F).

${ }_{66}$ Op. cit., p. 59. PAтo erróneamente afirma que "ningún investigador ha hecho referencia a la antigua moneda... que por aquel tiempo circulaba en Flandes y el Franco Condado" (op. cit., p. 4) seguramente por desconocer a estos autores antedichos. Asimismo, erróneamente expresa que esta moneda era "de lata con bordes irregulares", cuando por lo contrario era una importante moneda de plata, confundiendo el patagón de Flandes y el Franco Condado con el patacón español de cobre ya comentado por Deodat. Vemos que estos autores hacen referencia a cuatro monedas diferentes: posiblemente el patacón argentino (Lehmann Nitsche), el patacao portugués (Deodat), el patacón español (Deodat) y el patagón de Flandes (González y Pato). 
ter. p.-unköna To be on the water (of anything at all broad and flat). p.-u-nata, p.-öna To spead, to be or get broad, wide, spread abroad, widned, etc. p.-unur-kataka To get wider and wider, broader and broader, or more spread. p.-undek- $a$ To be spread abroad as the buildings of a city. To be or get flat. To fall abroad as a worn out canoe on the beach. p.-u.-wia To be lying as an old canoe all spread abroad on the shore. p.-unaina To fly or walk with widely outspread wings. p.-unagulu To widen out as the width of a river here and there by the receeding of its shores ${ }^{67}$.

Ritchie Key retoma este diccionario reproduciendo sólo los siguientes morfemas ${ }^{68}$ :

página 99: <u-patagön-a> 'Ampliar, ensanchar... Estirar, como cuando una persona estira sus brazos, alas, chaleco, etc.', Página 211: <kupata-gu-möni> 'Ir hacia (un lugar) y ampliar, o estirar los brazos', Página 372: < patag-önia > 'Para referirse a cualquier cosa o superficie ancha...', Página 555: < tupatag-öna > 'Extender, abrir hacia fuera... ${ }^{69}$.

Es realmente llamativo el significado de "patag"/"önia”, "patagönia" que según Thomas Bridge significaría "cualquier

${ }^{67}$ Thomas BRIDge, Yamana-English a dictionary of the speech of Tierra del Fuego, eds. Ferdinand Hestermann \& Martin Gusinde, Wien, 1933, p. 372. Morales (op. cit., p. 15) traduce: "patag y önia que traduce al inglés como "cualquier cosa o superficie ancha”; continúa con la frase ökan kö-p.ö-ta gömi, que fonéticamente tiene cierto parecido con Patagonia y que traduce como "en mi casa hay una tabla"; del mismo modo forma binomios con $p$. (abreviatura de patag) y umöci, 'se cae una casa mal construida'; $p$. y unköna, 'estar en el agua sobre una cosa ancha'; $p$. y öna, 'acción de ensanchar o desparramar'. Luego continúa con otros cinco binomios formados con los términos kataka, undeka-a, wia, unaina y unagulu, persistiendo en las traducciones la idea de ampliarse o desparramarse sobre variados accidentes geográficos".

${ }_{68}$ No reproducidos por Morales a excepción de patag-önia.

69 Marie Ritchie Key, "El significado de Patagonia", EFil, 2002, núm. 37, p. 3. Seguramente Ritchie Key no conoció el trabajo anterior de Morales, razón por la cual en el resumen de su trabajo expresa: "Presento aquí una posibilidad que me sugirió el estudio del Diccionario Yamana de Thomas Bridges" (p. 1). Previamente Ritchie Key expresa que Pigafetta "se refiere a los indios tehuelches como los «gigantes»" y que al dar posibles explicaciones al origen del término patagón, hay quienes identifican estos "gigantes" "con los personajes del mítico Primaleón de Grecia” (p. 2). En este caso, debemos aclarar que en el Primaleón aparecen varios "gigantes", pero a ninguno se lo relaciona con los "gigantes" de Pigafetta; sólo se relaciona a un personaje llamado "patagón” y que algunas veces se le llama "gran patagón”, pero nunca gigante, como veremos más adelante. 
cosa o superficie ancha”, esto nos recuerda precisamente las grandes y extensas planicies de la meseta patagónica, pero eso no concuerda con el hecho de que Magallanes nombra "patagones" a los indígenas que encuentra en la bahía de San Julián, mientras los yamanas vivían en la zona costera del sur de la isla de Tierra del Fuego, zona todavía por descubrir y por la cual Magallanes no pasaría; asimismo, los llama "gigantes", y los yamanas eran unos de los aborígenes de menor estatura de la zona patagónica, de alrededor de $1,50 \mathrm{~m}^{70}$.

Más recientemente, Enrique Pato observa una característica fisiológica,

que ha pasado inadvertida para todos los autores que se han interesado en la génesis del topónimo argentino... que en el gentilicio patagón la base patago no hace referencia a 'pie humano', sino a una enfermedad ${ }^{71}$.

Pato nos hace saber que en los tiempos de Magallanes se denominaba "patago" a una enfermedad que impedía "de ligero" mover la lengua, y que provocaba hablar "papo", observa que en la Historia general de Gómara ${ }^{72}$ se puede leer:

...que tienen disformes pies, por lo cual los llaman patagones. Hablan de papo, comen conforme al cuerpo ${ }^{73} \ldots$ [y] que debe relacionarse necesariamente con el hecho de que el tehuelche es

70 "Fuéguidos. Hombres de estatura baja... Yámana v. 1577, m. 1473" (Dick E. IbARra Grasso, Argentina indígena E prehistoria americana, TEA, Buenos Aires, 1971, p. 195).

71 Op. cit., p. 6. Morales (op. cit., pp. 14-15) ya había observado con anterioridad a Pato el término patagus como "enfermedad grave y mortal", pero lo descartó para su análisis.

72 Francisco López de Gómara, Historia general de las Indias, ed. cit., p. 218.

73 Pato, al hacer la cita de la obra de López de Gomara, detalla 1538 como año de impresión de la Historia General de las Indias, pero la primera edición de esta obra es de 1552. Quizás se ha confundido con la Historia general y natural de las Indias de Fernández de Oviedo, cuya primera edición es de 1535, aunque su segunda parte, que incluye el viaje de Magallanes, fue impresa por primera vez en 1557. Asimismo, PATo erróneamente incluye el siguiente comentario: "son todos muy ajudiados en gesto y habla, ca tiene grandes narices y hablan de papo" (op. cit., p. 6); pero estas son las características que le corresponden a los "hijos de la espuma del mar" que viven en manglares del Perú, que también transcribe Gómara (t. 2, p. 3). 
una lengua aglutinante, donde predominan los sonidos guturales y oclusivos ${ }^{74}$.

Resulta interesante la observación de esta característica de hablar de los patagones, pero entonces nos preguntamos por qué Pato resalta el hecho que Pigafetta,

gracias a la ayuda de uno de los indios patagones (Pablo) se entra en contacto con la lengua tehuelche... Pero no sólo el cronista puede 'conversar' directamente con estos indios, el contacto directo entre la tripulación y los tehuelches fue generalizado (p. 6),

aquí transcribe a Pigafetta "Pronunciaba tan claro como nosotros, sino que con resonantísima voz"; también llama la atención a que inmediatamente antes, Gómara acababa de expresar que por sus "disformes pies" los llamaban patagones y no por hablar "de papo". Debemos observar que Pigafetta en ningún momento hace referencia a esta forma de hablar y que Pato sólo toma esta característica "fisiológica" de Gómara ${ }^{75}$.

En 1956 Manfroni creía ver el origen del término "Patagoni" en los "patos" que los navegantes vieron por la región:

Dal contesto parrebbe che Magallano desee il nome di Patagoni a quel popoli perche vestivano di pelle dei 'patos', che sono i lupi marini, secondo alcune fonti: 'lobos y patos' dice il Herrera, facendo invece una distinzione.

Esta frase aparece como nota al pie de página luego de que Magallanes expresara que "nomino a questi popolo Patagoni. Tutti se vestono de la pelle de quello animale gia detto" (p. 71). En ningún lugar el "contesto" sugiere que las "pelle" son de patos y con referencia a "quello animale gia detto", el mismo Manfroni aclara que "La descrizione corrisponde, press'a poco, all'aspetto del guanaco, rumiante del genere lams, difusso nella Patagonia” (p. 67).

Casamiquela sugiere el término patagio y lo presenta de la siguiente manera:

74 PAтo, op. cit., p. 6.

75 Desconocemos cuál ha sido la fuente utilizada por Gómara para hacer esta afirmación, como también que otro cronista la haya observado. 
una palabra sugestiva como patagio (derivada de patagium), que denomina, en el castellano actual (y en otras lenguas, como el inglés) a una 'extensión del cuerpo' de carácter especial, como las alas de las aves o a las membranas que unen brazos con piernas en algunos anfibios con cierta capacidad de planear ${ }^{76}$,

inmediatamente toma este término y lo relaciona con pataccone: "incluso la palabra italiana a que acabo de referirme pataccone, bien pudo dar origen a patagón; tal vez no surgió de la obesidad misma de la persona sino de los múltiples pliegues de piel derivados de ella"77; luego sugiere relacionar esta característica de "múltiples pliegues de piel" con "las enormes orejas" de un personaje llamado patagón incluido en la novela de caballerías Primaleón (novela y personaje que analizaremos más adelante), concluyendo: "Pues, clarísimo está también, ellas [las orejas], colgantes, constituirían un patagio de primer orden... valdría como 'de piel colgante'; para el caso 'orejudo"”78.

76 Rodolfo Casamiquela, "Los gigantes patagones y la ciudad de los Césares", Todo es Historia, Buenos Aires, 2007, núm. 477, p. 9.

77 Id. CASAmiQuela algunas líneas antes expresaba: "O la italiana pataccone, consignada por Morales, aparentemente emparentada con 'persona obesa, lenta para operar"” (p. 8). Morales, al respecto y alejándose de pataccone como origen del topónimo Patagonia, expresa: "el Vocabulario Italiano de Rigutini y Fanfani (1903) tiene incorporado el compuesto 'pataccóneóna', que aparece definido como 'persona obesa, lenta para operar'. Bien sabemos que los tehuelches eran nómades que vivían de la caza del ñandú y el guanaco; no concuerda, entonces, caracterizarlos como obesos y lentos" (op. cit., p. 14).

${ }^{78}$ Op. cit., p. 11. Con referencia a esta hipótesis, no compartimos que los "múltiples pliegues de piel" de estos aborígenes sea algo distintivo o característico. Observamos las imágenes que nos presenta el mismo autor en su trabajo compartido: Rodolfo M. Casamiouela, Osvaldo Mondelo, Enrique Perea y Mateo Martinic Beros, Del mito a la realidad, evolución iconográfica del pueblo tehuelche meridional, Fundación Ameguino, Viedma, 1991, donde podemos ver caras con y sin arrugas, dependiendo de la edad. Es cierto que quizás éstas aparecieran prematuramente por las inclemencias climáticas de las zonas australes y la vida a la intemperie, pero seguramente también deberían aparecer prematuramente en los navegantes durante sus travesías en alta mar. Casamiquela sugiere que el término patagón, de la novela de caballerías, derivaría de patagio, y que el autor del Primaleón utilizó este término teniendo en cuenta "las grandes orejas que le llegan hasta los hombros"; al respecto podríamos decir que hubiese sido más fácil llamarlo orejón u orejones, término que encontramos en el Tesoro de la lengua castellana de Sebastián de Covarrubias (ed. de Martín de Riquer, S.A. Horta, I.E., Barcelona, 1943, p. 839) a diferencia de patagio que no aparece. 
Hay quienes observan el origen de este nombre en términos relativos a la proporción de la altura de los patagones medida en codos. Francis Fletcher, capellán de Francis Drake, quiso observar "pentagones" y "pentagours" en lugar de "patagones" y "patagón":

Magellane was not altogether deceived, in naming of them Giant... and thereupon might presume the more boldly to lie: the name Pentagones, five cubits, viz.7. foot and half, describing the full height (if not some what more) of the highest of them ${ }^{79}$;

expresando anteriormente "whom Magallanes named Patagous or rather Pentagours from their huge stature, and strength proportionable" (p. 26). Lida de Malkiel, en su Fantasía y realidad, al respecto de este último origen nos aclara: "en su muy problemático griego querría decir hombres de cinco codos de estatura" (p. 219). Morales nos presenta también otra teoría similar, donde

El Dr. Boeri opta por no apartarse de la lengua tehuelche, donde 'pata' es término 'siete' y 'gon' designa a 'codo'; o sea 'hombres altos', de unos 'siete codos' (2 m aproximadamente) (p. 15).

\section{El TÉRMINO PATAGÓN ANTERIOR A MAGALlANES}

En 1947, Mary Patchell en su trabajo, The Palmerin romances in Elizabethan prose fiction, al hablar de la serie de monstruos y animales con los cuales los héroes y caballeros de las novelas de caballerías frecuentemente tenían que enfrentarse, expresa:

One of the most curious of these creatures is the monster Patagon, "the strangest misshapen and counterfeite creature in the world". He walks erect like a man, but has the face of a dog, a figure probably inspired by the dog-faced giant Ardan Canileo, in Amadis of Gaul ${ }^{80}$;

79 Francis Drake, Who is or may be a pattern to stirre up all heroicke and active spirits of these times, to benefit their countrey and eternize their names by like noble attempts. Being summary and true relation of four severall voyages made by the faid Sir Francis Drake to the West Indies, Nicholis Bourne, London, 1653, p. 28.

80 Mary Patchell, The Palmerin romances in Elizabethan prose fiction, Columbia University Press, New York, 1947, p. 46. 
más adelante especifica que en la novela Primaleon of Greece, su héroe Primaleón ${ }^{81}$ : "captures the monster Patagon, which becomes tame in the presence of ladies" (p. 131). En su nota de pie de página número 158, Patchell aclara (p. 46):

The connection between 'Patagon' and 'Patagonia', if any, is probably only etymological. The word 'patagon' means in Spanish 'large foot', and the South American country is said to have been so named in allusion to the large foot-prints found by Magellan, the first explorer (1520). New Int. Encyclopedia, 2d ed., 1927, XVIII, 152.

Como podemos ver, sólo le adjudica una "probable" relación etimológica, no aventurándose en más explicaciones se aviene con el significado de la Enciclopedia. Algunos años más tarde, en la Hispanic Review de octubre de 1952, Lida de Malkiel, comentaba:

A falta de conocimiento directo [del Primaleón], me sirvo del sumario inserto por Miss Mary Patchell en su trabajo The Palmerin Romances in Elizabethan Prose Fiction (Columbia University Press, 1947), pág. $131^{82}$,

presentando su nueva y revolucionaria teoría, al expresar que el término patagón utilizado por Magallanes en el año 1520 derivaría de la novela de caballerías Primaleón ${ }^{83}$.

Hemos encontrado que antes de Patchell, en 1908, Joseph de Perott ya había observado la existencia del nombre patagón en la novela de caballerías Primaleón y su relación con el igual término con que denominó Magallanes a los habitantes de las tierras australes. Perott publicó un artículo titulado "Il "gran patagone' nel 'Primaleone' e nei libri di viaggio di Pigafetta”; artículo citado por Eisenberg en su bibliografía de Castilian romances of chivalry ${ }^{84}$ y del que González se expresara así:

${ }^{81}$ De aquí en adelante escribiremos Primaleón (ya sea éste el título de la obra o el nombre del héroe) y patagón (como personaje de esta novela) con acentos, exceptuando las citas textuales.

82 "Para la toponimia Argentina: Patagonia", HR, 20 (1952), p. 323.

83 María Rosa Lida de Malkiel, "Sobre el origen de la palabra patagón”, Argentina Austral, 1953, núm. 263, pp. 14-15.

84 Daniel Eisenberg, Castilian romances of chivalry in the sixteenth century: A bibliography, Grant \& Cutler-Artes Gráficas Soler, Valencia, 1979, p. 83. 
su título hace suponer que el descubrimiento de Lida ya había sido realizado cuarenta y cinco años antes. Lamentablemente, no hemos podido localizar el trabajo de Perott, e inferimos que tampoco lo han conocido los estudiosos que, en su totalidad y al margen de su postura de adhesión o de rechazo, reaccionaron ante la tesis de Lida como ante una radical innovación (p. 17).

Perott allí dice:

Nello scorrere la traduzione italiana dei tre libri di Primaleone fatta da Mambrino Roseo e stampata a Venezia nel 1608 (l'originale spagnuolo risale com'e noto al 1512), e nel considerare come un esemplare dell'originale abbia potuto verisimilmente trovarsi a bordo della 'Vittoria', la nave montata dal viaggiatore italiano Pigafetta, mi nasce il dubbio che quest'ultimo abbia tratto piú di una notizia dal romanzo spagnuolo ${ }^{85}$.

Como puede verse, Perott piensa que sería factible que se encontrara una copia del Primaleón en la nave Victoria y no sólo que Pigafetta haya estado informado al respecto. Inmediatamente transcribe para su comparación algunas características comunes entre el patagón de la crónica de Pigafetta y el del Primaleón:

Si metta infatti a raffronto quel che si legge nel cap. XXXI del Libro di Primaleone coi seguenti passi del libro di bordo di Pigafetta: Primaleone... uiuono come animali mangiando carne cruda... vestiti di pelle di fiere... cambatté con uno di cotesti Patagoni... pose una gra catena al pié... Pigafetta... il Capitano fece portar duoi ferri di quelli che si mettono alli piedi, E fece metterli loro alli piedi... Il Capitan generale chiamó qsti popoli Patagoni... vestono della pelle del Animal... viuono di carne cruda (p. 290).

Seguidamente destaca: "Anche il modo di curarsi che avrebbero i Patagoni in caso di malattia trova rispondenza presso Primaleone (f. 318) e Pigafetta (f. 354)" (p. 291). Perott en ningún momento analiza el origen del nombre patagoni, sólo se limita a hacer las comparaciones antedichas; pero el título de su trabajo es más que sugestivo: "Il 'gran patagone' nel 'Primaleone' e nei libri di viaggio di Pigafetta”. Si entendemos por lo

85 Joseph de Perott, "Il 'gran patagone' nel 'Primaleone' e nei libri di viaggio di Pigafetta”, Studi di Filologia Moderna, 3/4 (1908), p. 290. Este artículo lo hemos encontrado en la Biblioteca Nazionale Centrale di Roma. 
dicho por Perott, que Pigafetta tomó el nombre patagoni de la novela de caballerías que "potuto verisimilmente trovarsi a bordo", tendríamos que confirmar la duda ya planteada por González de que "el descubrimiento de Lida ya había sido realizado cuarenta y cinco años antes" (p. 17).

\section{El PRIMALEÓN}

El Primaleón, también llamado Libro segundo del emperador Palmerín es la continuación del Libro del famoso cavallero Palmerín de Olivia ${ }^{86}$ editado en diciembre de 1511; al respecto de estos dos libros, Lida de Malkiel nos hace saber que:

tuvieron éxito inmediato, gran número de ediciones y traducciones al italiano, francés e inglés. Pocos libros pueden jactarse de haber tenido entusiastas más ilustres o más refinados que el Primaleón: Fernando de Rojas, Bartolomé de Torres Naharro, Gil Vicente, Juan de Valdés, Garcilaso de la Vega, Torquato Tasso, Tirso de Molina, fray Hortensio Paravicino ${ }^{87}$.

La primera edición del Primaleón fue impresa en Salamanca en el año $1512^{88}$ y la única copia conocida en la actualidad se encuentra en la Cambridge University Library ${ }^{89}$. Existe una siguiente edición publicada en 1516 que Eisenberg había excluido de su Castilian romances of chivalry in the sixteenth century; pero la ha vuelto a considerar ${ }^{90} \mathrm{y}$ actualmente se encuentra incluida

${ }^{86}$ Equivocadamente, Perla Zusman expresa que el término patagón se encuentra en la novela Palmerín de Oliva, en su nota número 7: "¿Terra Australis-Res Nullius. El avance de la frontera colonial hispánica en la Patagonia (1778-1784)?”, en Scripta Nova. Revista Electrónica de Geografía y Ciencias Sociales, Universidad de Barcelona, núm. 45 (34), 1 de agosto de 1999 (www.ub.es/geocrit/sn-45-34.htm, consultado el 4 de mayo de 2007).

87 Fantasía y realidad, p. 219.

88 Esta edición está incluida en el índice de impresos en España entre 1501 y 1520 de Norton (F[rederick] J[ohn] Norton, Printing in Spain 15011520, Cambridge University Press, 1966, p. 199).

${ }^{89}$ Este ejemplar aceptado como princeps es el que utilizamos para realizar el presente trabajo (F.151.b.8.8), el cual cotejamos con la edición de Marín Pina (Primaleón, Salamanca 1512, Centro de Estudios Cervantinos, Alcalá de Henares, 1998). En adelante, las referencias al Primaleón son a esta edición.

90 "Pero he vuelto a considerarla documentada, y la he vuelto a incluir en la nueva bibliografía que ultimamos María Carmen Marín Pina y yo”, 
en la bibliografía de novelas de caballerías publicada en el año 2000 conjuntamente con Marín Pina ${ }^{91}$.

Acerca del Primaleón, Leonard nos comenta que: "debe haber gozado de gran simpatía en las Indias, a juzgar por el hecho de que aparece con mayor frecuencia que otros libros de caballerías" ${ }^{2}$, pudiéndose observar esta frecuencia en sus registros publicados en Romances of chivalry in the Spanish Indies ${ }^{93}$.

\section{El patagón del PRIMALEÓN}

El nombre patagón aparece por primera vez en la novela Primaleón en el capítulo 133, cuando el héroe Primaleón y alguno de sus compañeros llegan a una isla innominada; allí el Señor de ésta, llamado Palantín, a la pregunta de Primaleón de cómo es su isla y quiénes la habitan, contesta:

la mayor población que ella tiene es enla co / sta dela mar y a vna parte desta ysla ay muy gran / des montañas y de poco tiempo a esta parte / parte $[s i c]$ moran enellas vna gente muy partada / de todas las otras que ay enella porque biven / ansi como animales y son muy bravos y esqui / vos y comen carne cruda delo que caçan por / las montañas y son ansi como salvajes que no / traen sino vestiduras de pieles delas anima / lias que matan y son tan desemejadas que es co / sa maravillosa de ver mas todo es nada con / vn hombre que agora ay entrellos que se / llama patagon [lo resaltado es nuestro] (f. cxxix [cxxxiii]r).

\footnotetext{
"Inexactitudes y misterios bibliográficos: las primeras ediciones de Primaleón" (http://users.ipfw.edu/ jehle/ DEISENBE/Other_Hispanic_Topics/ Inexactitudes_y_misterios_b ibliograficos-_las_primeras_ediciones_de_ Primaleon.htm, p. 1 consultado agosto 2006).

91 Daniel Eisenberg y María Carmen Marín Pina, Bibliografía de los libros de caballería castellanos, Prensas Universitarias de Zaragoza, 2000, p. 409.

92 Irving A. Leonard, Los libros del Conquistador, F.C.E., México, 1953, p. 101.

93 Irving A. Leonard, "Romances of chivalry in the Spanish Indies. With some «registros» of shipments of books to the Spanish colonies", $M P h$, 16 (1933), pp. 275, 306, 309, 312, 321-327. РATo, al enumerar a los autores que se adhieren a la idea del origen del término patagón en el Primaleón, erróneamente incluye a Leonard con su obra "Romances of chivalry in the Spanish Indies". Allí Leonard sólo enumera la obras leídas por los conquistadores, incluyendo al Primaleón, pero en ningún momento expresa comentario sobre el patagón de esta novela (op. cit., p. 2).
} 
Resumidamente, diremos que Primaleón junto con otros caballeros se adentran en esta isla logrando capturar al patagón y liberar de sus males a los habitantes. Luego Primaleón deja la isla llevando en sus naves al patagón capturado rumbo a Apolonia. Al llegar se lo entrega a su reina Gridonia, que

...ante la hermosura de Gridonia y la cordialidad de Zerfira [la infanta] que desde este momento se encargará de su cuidado, el Patagón aplaca su ira y pierde su mal talante ${ }^{94}$.

Finalmente, luego de participar en diferentes peleas, cacerías y desencuentros, el "gran patagón" ingresa a Constantinopla junto a Gridonia, siendo el siguiente párrafo la última vez que aparece en esta novela:

...y el gran patagon yva / ante gridonia lleuando de trailla al leon y la / gran fealdad de patagon acrecentaua la gran / fermosura de Gridonia (cap. 189, f. cxcix $r$, lo resaltado es nuestro).

\section{¿Magallanes Pudo haber leído el Primaleón?}

Podemos decir que tanto Magallanes como Pigafetta eran personas relacionadas con la aristocracia de su época y por lo tanto con acceso a su literatura contemporánea. De Magallanes se sabe que "Era hombre noble" 95 , Fernández de Navarrete nos hace saber que en "el año 1512... era mozo fidalgo de la Casa Real... y al siguiente ya había sido promovido de mozo fidalgo á fidalgo escudeiro" (p. xxix), "esa descendencia asegura a Magallanes el derecho de usar y heredar un escudo propio y le da libre acceso a la corte. Afírmase que en su primera juventud prestó servicio de paje a la reina Leonor" ${ }^{66}$ y Carlos V "le hizo caballero de Santiago"97; al decir de Bataillon: "eran hombres cultos Colón

94 María Carmen Marín Pina, Primaleón (guía de lectura), Centro de Estudios Cervantinos, Alcalá de Henares, 2003, p. 85.

95 Antonio de Herrera, Historia general de los hechos de los castellanos en las Islas i tierra firme del mar océano. Década segunda, Madrid, 1601, libro 2, p. 66.

96 Stefan Zweig, Magallanes. (La aventura más audaz de la humanidad), Claridad, Buenos Aires, 1938, p. 31.

97 Antonio Pigafetta, Primer viaje en torno del globo, Espasa-Calpe, Buenos Aires, 1941, p. 27. 
y Vespucci, Magallanes y Hernán Cortés" ${ }^{98}$. No opina lo mismo Pato que expresa: "como bien demuestran los testimonios de los historiadores que han estudiado la figura de Magallanes, no era ningún entusiasta de la lectura de este tipo de novelas" (p. 3).

Al respecto de Pigafetta, también "Era de familia hidalga... célebre en toda Europa por sus excelentes conocimientos en filosofía, matemáticas y astrología (Storia di Vienza, all'anno 1480)"99; en primera persona comenta:

en el año 1519 estaba yo en España en la corte de Carlos V, rey de Romanos, con monseñor Chiericato, entonces protonotario apostólico y predicador del papa León X... Por los libros que yo había leído y por las conversaciones que tuve con los sabios que frecuentaban la casa del prelado (p. 51).

Con respecto a las novelas de caballerías podríamos destacar, al decir de Bataillon, que "Nadie negará la afición de los aventureros y de los soldados a la literatura de aventuras que encantaba también a los cortesanos" (p. 38).

Dicho esto, serían entonces las ediciones de 1512 o la de 1516 las que podría haber leído Magallanes y que Pigafetta no necesitó aclarar al incluir el término patagon en su relato. Como ya lo expuso Perott: "un esemplare dell'originale abbia potuto verisimilmente trovarsi a bordo della "Vittoria" (p. 290), o como bien ha expresado Battini: "Seguramente su lectura y su comentario entretuvieron las veladas del crudo invierno de 1520, pasado en aquella tierra desolada" (p. 158). Al decir de Lida de Malkiel: "Sin duda Pigafetta no creyó necesario glosar la designación impuesta por Magallanes y familiar a todos por la leidísima novela"100.

\section{El patagón de Magallanes y el del Primaleón}

Ahora bien, veamos cuáles son las coincidencias y similitudes que podemos observar entre el patagón de Magallanes y el patagón del Primaleón ${ }^{101}$ :

98 Marcel Bataillon, "Acerca de los patagones retractatio", Fil, 8 (1962), p. 38 .

99 Antonio Pigafetta, Primer viaje en torno del globo, pp. 34-35.

100 Para la toponimia, p. 323.

101 En cada caso no necesariamente transcribiremos todas las veces que aparece la misma característica común en el mismo texto. 


\section{Coincidencias}

a) Se visten con pieles de animales.

Pigafetta: "era vestito de pelle de animale" (f. $7 r$ ).

Primaleón: "no / traen sino vestiduras de pieles delas anima / lias que matan" (cap. 133, f. cxxix [cxxxiii]r).

b) No es uno sino son varios los patagones.

Pigafetta: "li nostri ne condussero ale navi dizidoto [patagones]" (f. 8r).

Primaleón: "vinieron / bien quinze dellos [patagones]" (cap. 134, f. $\operatorname{cxxx}[\mathrm{cxxxiv}] r)$.

c) Llevan arcos y flechas.

Pigafetta: "et nella mano [traía] uno archo curto et grosso... con uno mazo / de frece de canna non molto longue inpenade como le nostre" (f. $7 v$ ).

Primaleón: "trae vn arco en sus manos con saetas / muy agudas con que fiere" (cap. 133, f. cxxix [cxxxiii]r).

d) Se observa la presencia de mujeres.

Pigafetta: "et le sue femime cargate como asine" (f. 7v).

Primaleón: "que ouo que auer con v / na de aquellas patagonas" (cap. 133, f. cxxix [cxxxiii]r).

e) Son necesarios varios hombres para sostenerlos.

Pigafetta: "apena potesemo / legarli li mani li mandassemo aterra con nove homini" (f. 8v).

Primaleón: "lo leuenta / ron por fuerça y seys hombres de pie que venian con / palantin lo tomaron entresi para lo llevar" (cap. 134, f. $\operatorname{cxxx}[\mathrm{cxxxiv}] r)$.

f) Son veloces corredores.

Pigafetta: "Certamente questi giganti / Coreno piu cavali" (f. $9 r$ ).

Primaleón: "corren tan ligero que no ay quien lo pueda alcan / çar” (cap. 133, f. cxxix [cxxxiii]r).

g) Se alimentan con carne cruda.

Pigafetta: "viveno de carne cruda" (f. 9v).

Primaleón: "comen carne cruda delo que caçan por / las montañas" (cap. 133, f. cxxix [cxxxiii]r).

h) Poseen métodos de autocuración. 
Pigafetta: "Quando questa gente se sente malle al stomacho in loco de purgarse se meteno / nela golla dui palmi et piu duna friza... quando li dole el capo se danno nel / fronte una tagiatura nel traverso et cussi nele brace ne le gambe et in / ciascuno locho del corpo cavandosse molta sangue" (f. $9 r$ ).

Primaleón: para curarse las heridas "el mesmo se entendia de curar y saco / la lengua muy grande y bermeja y començo de / lamber las feridas y deziale que aquello le bastaria" (cap. 135, f. $\operatorname{cxxx}[\operatorname{cxxxiv}] v)$.

\section{Similitudes}

a) $\mathrm{Su}$ altura.

Pigafetta: "Undi alinproviso vedessemo uno homo de statura de gigante" (f. $7 r$ ), "Deli a 6 jorni fu visto uno gigante" (f. $8 r$ ), "Passati 15 giorni vedessemo quatro de questi giganti" (f. 8v).

Primaleón: a decir verdad nunca aparece el patagón como gigante, pero son varias las oportunidades que se lo califica como "gran": "con su escude / ro topo al gran patagon" (cap. 134, f. cxxix [cxxxiii]r.), "y saco su espa / da y llego al gran patagon", "fue sobre el gran / patagon". Obviamente "gigante" no es lo mismo que "gran", más cuando en el Primaleón aparecen varios gigantes y como tal son llamados; pero no podemos dejar de observar que también "era grande de cuerpo y de gran fuerça" (cap. 134, f. cxxix [cxxxiii]v).

b) Ambos son encadenados para ser llevados ante sus respectivos soberanos.

Pigafetta: "per condurli in spagnia... Il capitano / generale fece portare dui para de feri che se meteno ali piedi [cepos]... Subito a duno medesimo tempo li fece metere a tucti dui / et quando linquiavano con lo fero que traversa dubitavano ma segurandoli il / capitano pur steteno fermi avedendose poi de lingano sbufavano come tori / quiamando fortemente setebos" (f. 8v).

Primaleón: "tomole en voluntad de lo lleuar preso... porque su señora Gridonia [en Constantinopla] lo viesse... fue por la / cadena en que el gran patagon traya los leones /...fueron a patagon y echa / rongela ala garganta aun que el fazia tales cosas / que los espantaua que daua grandes bramidos / por manera que acudieron alli dos de aquellos pa / tagones de su linaje" (cap. 134, f. cxxix [cxxxiii]v). En ambos casos dan fuertes gritos, ya sea sbuffando, ya sea bramando seguramente pidiendo socorro, uno a su dios "setebos"102 y el otro a los "patagones de su linaje". Obviamente

102 Es interesante que William Shakespeare tome este nombre "Setebos", para incluirlo en su novela The tempest. En el acto I, escena II, el gigante "Cali- 
esto es sólo una similitud literaria, ya que Magallanes seguramente no les puso los grilletes a estos aborígenes por haberlo leído previamente en el Primaleón, pero creemos que vale la observación.

\section{c) Su fealdad.}

Pigafetta en ningún momento habla acerca de estas características explícitamente, pero no dejamos de observar lo afirmado por Lida de Malkiel: "su pintarrajeado semblante, tal como lo describe Pigafetta, no deja de recordar el de los gigantes perrunos de los libros caballerescos ${ }^{103}$ : «Tenía el indio que subió a la nave de Magallanes el rostro grande y pintado de rojo, y alrededor de los ojos de amarillo, y en medio de las mejillas tenía pintados dos corazones; sus pocos cabellos estaban teñidos de blanco»"104,

ban", cual si fuese un "gigante patagón" expresa: "It would control my dam's god, Setebos, and make a vassal of him" (Comedy of the tempest, ed. with notes by William J. Rolfe, New York, 1884, p. 49), aparece nuevamente en el acto V, escena I: "O Setebos, these be brave spirits indeed!" (p. 103). En nota 371 de esta edición, se puede leer: "probably got this name from the account of Magellan's voyage in Robert Eden's History of Travaile (A.D.1577)” (p. 120); al respecto RICHARD EDEN expresa: "they [los patagones] roared lykes bulles, and cryed uppon their great devill, Setebos, to help them" (The history of travayle in the West and East Indies, London, 1577, p. 434). PAul Groussac expresa que: ''Setebos' est un mot téhuelche (il's n'existe pas en araucan); il figure dans una liste intercalée dans le Vocabulaire Pampa, du Colonel Barbará" (op. cit., p. 414). Con respecto a que setebos "n'existe pas en araucan", Bertha KOESSLER-ILG en su trabajo de recopilación de mitos, leyendas y tradiciones mapuches informa que sí ha existido y su "historia Nro. 8" precisamente la titula: "Setevo, la diosa que recibió cinco corazones" (Cuentan los araucanos, Nuevo Extremo, Buenos Aires, 1997, pp. 38-41). Creemos que hasta ahora nadie ha observado esta coincidencia entre el nombre de la divinidad mapuche con lo expresado por el patagón capturado por Magallanes.

103 Con respecto a los hombres con rostros de perros, Lida DE MALKiel comenta en Fantasía y realidad, pp. 219 y 220, que era una característica "repetida hasta la saciedad en tratados medievales... No sorprende, pues, que el Amadís dedique un largo capítulo (II, 18) al combate del héroe con el monstruo Ardan Canielo, y que le describa puntualmente: «No era descomunalmente grande de cuerpo, pero era más alto que otro hombre que gigante no fuese...; el rostro había grande e romo, de la fechura de can..., y era todo brasilado e cubierto de pintas negras espesas..., e había brava catadura»".

104 Ibid., p. 220. María LaURa De ARRIBA, en "Los sonidos de la enunciación en la primera vuelta al mundo", al hablar del origen del término patagon, confunde la descripción del rostro del "patagón" que observa Pigafetta y se lo adjudica al "patagón" del Primaleón: "En él [el Primaleón] aparece un monstruo de figura humana y cara de perro, con «el rostro ancho y teñido de rojo, con los ojos circulados de amarillo, y con dos manchas en forma de corazón en las mejillas»” (p. 65). Allí detalla que toma esta información del trabajo de Livon-Grosman. A decir verdad, en este último trabajo, no queda 
afirmando en Para la toponimia Argentina que "su semblante... debía ser poco menos espantable” (p. 323), pero dejando claro que "los fornidos aborígenes de la costa atlántica, a buen seguro, no lucían hocico de perro"105.

Con referencia a esta fealdad podemos ver en el patagón del Primaleón que "su catadura era espantosa... Selvida que ansi se llamaua la fija del ca / vallero señor dela ysla vino por verlo [al patagón] y estra / ñamente fue espantada por mirallo" (cap. 135, f. $\operatorname{cxxx}[\operatorname{cxxxiv}] v)$.

Creemos que resulta importante observar que sólo esta última característica en común entre ambos patagones (fealdad) es la que pudo conocer Lida de Malkiel al haber leído solamente (como quedó dicho con anterioridad) el resumen de Patchell, desconociendo, por lo tanto, todas las anteriores.

Marín Pina al respecto de la fealdad expresa: "La fealdad tiene varias caras y encierra un contenido moral y emocional más complejo que la belleza"106.

d) Su salvajismo.

Pigafetta no los califica explícitamente de salvajes, pero podemos leer: "tutti se vesteno de la pelle / de quello animale gia deto non anno case senon trabacque de la pelle del / medesimo animale et con quelli vano mo di qua mo di la como fanno li / cingani viueno de carne cruda... et mangiauano li sorgi / senza scorticarli" (f. 9v).

Primaleón: "y son ansi como saluajes... y dizen que ouo que ayer con $\mathrm{u}$ / na de aquellas patagonas que ansilas llama / mos nosotros por saluajes" (cap. 133, f. cxxix [cxxxiii]r).

Marín Pina al respecto del salvajismo nos aclara:

Una de sus faces nos la ofrece el retrato del salvaje... Los patagones descubiertos por Primaleón no son sino una tribu de salva-

del todo claro si estas características le corresponden a los dichos de Pigafetta o al Primaleón: "En una de sus aventuras Primaleón apresa al Patagón que se caracteriza tanto por su mansedumbre frente a las damas como por su monstruosidad: tiene figura humana pero rostro de perro. Si comparamos esta descripción con la de Pigafetta, el relato de Primaleón hace aún más evidente la conexión: «el rostro ancho y teñido de rojo, con los ojos circulados de amarillo, y con dos manchas en forma de corazón en las mejillas»" (ERNESTO Livon-Grosman, Geografías imaginarias, el relato de viaje y la construcción del espacio patagónico, Beatriz Viterbo Editora, Rosario, 2003, p. 45).

105 Fantasía y realidad, p. 220.

106 En su ed. cit., p. 433. 
jes... El vocablo "patagones", con el que Hernando de Magallanes calificó también pocos años después a los aborígenes de la costa atlántica sur, es en el libro [de Pigafetta] sinónimo de salvaje ${ }^{107}$.

\section{El cuerno del patagón del Primaleón}

Leyendo la novela, vemos que el patagón lleva colgando de su cuello un cuerno: "y trae vn cuerno a su cuello / y taniéndolo vienen muchos de aquellos patago / nes" (cap. 133, f. cxxix [cxxxiii]r) y más adelante: "y torques / fue a tomalle el cuerno que traya al cuello [el patagón] que era / muy estraño y púsolo ala boca por ver que son fa / zía" (cap. 134, f. cxxx [cxxxiv] r). Pues bien, hemos encontrado en el Diccionario técnico de la músi$c a$ de Felipe Pedrell el siguiente instrumento musical: "Paflagonia: Antigua trompeta ó clarín cuyo pabellón tenía la forma de una cabeza de buey"108. Nos llamó la atención la similitud entre el nombre de este instrumento musical Paflagonia con los topónimos Patagonia y Paphlagonia (del griego П $\alpha \lambda \alpha \gamma o v i \alpha)$; este último denominado en su forma castellana Paflagonia ${ }^{109}$, al igual que el instrumento musical.

107 Op. cit., pp. 433-434.

108 Felipe Pedrell, Diccionario técnico de la música, Barcelona, 1899, p. 343.

109 Leemos en el Diccionario del mundo clásico, Labor, Barcelona, 1954, t. 1, p. 1238: "Paflagonia (П $\alpha \lambda \alpha \gamma o v i \alpha$, Paphlagonia). Comarca costera del Asia Menor, situada entre el Ponto Euxino al norte, la Bitinia al oeste, la Galacia al sur y el río Halys, que le separaba del reino del Ponto, al este... Su territorio era escaso en recursos naturales a causa de la abundancia de montes". Con respecto a su significado, RIHARD LEONHARD observa el origen de este topónimo en la voz griega $\pi \alpha \phi \lambda \alpha \zeta_{\varepsilon t v}=$ schwatzen agenähert [paphlázein = charlar, parlotear]" (Paphlagonia reisen und forschungen im nördilchen kleinasien, Berlin, 1915, p. 301), el profesor Cavallero define $\pi \alpha \phi \lambda \alpha َ \zeta \varepsilon ı v$ como "bullir, hervir; hervir de cólera o de indignación; por analogía hacer ruido" (comunicación personal); Leonhard en nota número 1 de pie de página aclara que esto fue detallado por Aristófanes: "So wird er schon richtig erklärt in

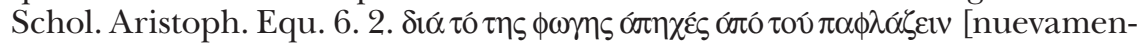
te Cavallero lo define como "la discordancia de la voz a partir del hervir de cólera”] wegen des unangenehmen Klanges, vom Schwatzen” (ibid., p. 301). Leonhard lo relaciona con la forma en que los eslavos denominaban a los germanos: "Njemetz" ("Nemec", los mudos), como los hombres que no saben hablar bien: "und ist ein Seitenstück zum Njemetz der Slawen, dem Manne, der nicht richtig sprechen kann". Entendemos por este último comentario que quizás no se les entendía cuando hablaban y que esto mismo ocurría con los paphlagones, ya sea por que no se les entendía su lengua y/o porque hablaban un mal o inentendible griego. Observando esto, pensamos 
Hemos tratado de encontrar información relacionada con este instrumento consultando diccionarios musicales ${ }^{110}$ y realizando consultas a diferentes especialistas ${ }^{111}$, pero no hemos podido encontrar ninguna referencia del mismo. Luego intentamos buscar este instrumento en diccionarios y enciclopedias de índole general, encontrándolo solamente en algunos diccionarios y enciclopedias de editoriales españolas tales como: Enciclopedia del idioma de Alonso ${ }^{112}$, Diccionario hispánico univer$s a l^{113}$ y en la Enciclopedia vniversal ilustrada ${ }^{114}$. Estos transcriben la misma descripción que aparece en la edición de Pedrell. Sin embargo, no aparece en el novísimo Diccionario de la música es-

que puede existir algún tipo de relación con el origen del nombre de la enfermedad patagus, también llamada papo (enfermedad ya comentada por Morales y Pato) que precisamente se caracterizaba por impedir hablar bien y que por lo tanto impedía entender correctamente lo expresado.

110 Hemos consultado, The new Grove dictionary of music and musicians (Stanley Sadie, Macmillan, London, 1980), The new Grove dictionary of musical instruments (Stanley Sadie, Macmillan, London, 1984), Diccionario de instrumentos Musicales de Andrés Ramón (Bibliograf, Barcelona, 1995), Diccionario Oxford de la música de Percy Alfred Scholes (Sudamericana, Buenos Aires, 1964), Dictionnarie critique de la musique ancienne et moderne de André Coeuroy (Payot, Paris, 1956), Dictionnaire de la musique, science de la musique de Marc Honegger (Bordas, Paris, 1976), Musical instruments of the World: An illustrated encyclopedia (Diagram Group, Paddington Press, New York, 1976) y Diccionario Harvard de música de Don Randel (Alianza, Madrid, 1997), entre otros.

111 Profesor Albert R. Rice de la American Musical Instrument Society (comunicación personal, agosto 2006), doctor Kenneth Moore del Metropolitan Museum of Art de New York (comunicación personal, agosto 2006), doctor Silke Berdux, curador de instrumentos musicales del German Museum de Munich (comunicación personal, abril 2001), Beatrix Darmstädter del Kunhistorische Museum de Viena (comunicación personal, abril 2001), con la Edinburgh University Library (comunicación personal, septiembre 2006), Sara Guastevi del Museo de la Música de Barcelona (comunicación personal, octubre 2006) y Yolanda Velo de la Asociación Argentina de Musicología (comunicación personal, septiembre 2006).

112 Martín Alonso, Enciclopedia del idioma, diccionario histórico y moderno de la lengua española (siglo XII al XX) etimológico, tecnológico, regional e hispanoamericano, Aguilar, Madrid, 1982, t. 3, p. 3093.

113 Diccionario hispánico universal, enciclopedia ilustrada en lengua española, W.M. Jackson, Buenos Aires, 1954, t. 1, p. 1053.

${ }_{114}$ Enciclopedia vniversal ilvstrada evropeo-americana, Espasa-Calpe, Madrid, 1930, t. 40, p. 1458. 
pañola e hispanoamericana (SGAE) ${ }^{115}$. Esto nos hace suponer que posiblemente, tomando como fuente informativa el Diccionario técnico de la música de Pedrell, algunos diccionarios y enciclopedias de ediciones españolas hayan incorporado este instrumento musical, pero dada la falta de información referida al mismo, haya quedado excluido del editado por la Sociedad General de Autores y Editores. Ahora bien, ¿dónde se informó Pedrell acerca de la existencia de este instrumento musical?, carecemos de respuesta. Con referencia a cuál era este instrumento, sólo conocemos la descripción antedicha y nada más. Por su nombre, creemos que debe estar directamente relacionado con la región geográfica que fue denominada de la misma forma: Paflagonia, y que bajo este nombre, perteneció al imperio persa, a la magna Grecia y al imperio romano, y que hoy es parte de la costa norte de Turquía, sobre el Mar Negro. Pero veamos, Pedrell nos informa que su "pabellón tenía la forma de una cabeza de buey", pues bien, entendemos que en este caso, buey o toro son similares, y es sabido el lugar preferencial que tenían estos animales en la cultura griega y persa ${ }^{116}$. Creemos que es verosímil pensar, por lo tanto, que exista una relación entre este instrumento y esta región geográfica, sobre todo cuando Pedrell nos aclara que esta trompeta o clarín es antiguo: "antigua trompeta ó clarín", a pesar de que no nos da una idea de cuán "antigua" es.

Un cuerno, como llevaba colgado el patagón en su cuello, no es una "trompeta" o "clarín", sin embargo, ambos son instrumentos de viento, y el cuerno se encuentra en la génesis de estos instrumentos.

\section{LA isla del patagón en la PAflagonia griega}

Ahora bien, ¿podría existir alguna relación geográfica entre la isla donde habitara el patagón del Primaleón con la región de la Paflagonia?

115 Diccionario de la música española e hispanoamericana, Sociedad General de Autores y Editores, Madrid, 1999, t. 8.

116 En Grecia, los bueyes y los toros eran los animales favoritos para celebrar holocaustos en las fiestas; observamos que fue toro en lo que se transformó Zeus para raptar a Europa. Hércules, en su segundo trabajo, debía capturar al toro sagrado que Minos, rey de Creta, tenía en su isla. En Persia aparece cuando Mitra mata al toro sagrado y al caer su sangre en la tierra surgen todas las plantas y animales. 
Tomamos el resumen que nos brinda Marín Pina en su guía de lectura del Primaleón y observamos que "sus primeras apariciones [de Primaleón] son como anfitrión de la corte griega" en Constantinopla, de allí, por tierra, llega a Ormedes y luego se traslada a Apolonia, de allí parte embarcado y una tormenta lo lleva a la villa de Turaz, luego se dirige a la isla de Cíntara y de allí a la isla innominada donde habita el patagón, desde donde regresa embarcado nuevamente a Apolonia ${ }^{117}$. En este periplo observamos como topónimos reconocibles Constantinopla y Apolonia.

Bien sabemos dónde queda Constantinopla, pero encontramos que son varios los sitios que se denominaban Apolonia ${ }^{118}$, podríamos decir que cualquier población que tuviera un templo dedicado al dios Apolo podría ser llamada así. Pero de todas ellas existió una sobre el Mar Negro, donde se encuentra la actual ciudad búlgara de Sozópolis, que tuvo "una estatua del dios de tamaño colosal”, que "alcanzó gran importancia comercial por su magnífica situación y por los dos puertos, que sirvieron de escala para los tráficos el Ponto ${ }^{119 "}$ (Diccionario del mundo clásico, p. 119) y fue la única en ser llamada Apollonia $M a g n a^{120}$. Al ser ésta la Magna, la "Gran Apolonia", nos está indicando su supremacía sobre las demás Apolonias ${ }^{121}$.

Ahora bien, veamos, desde esta Apolonia, ciudad puerto sobre el Mar Negro, navegando, luego de pasar por otras islas, llega Primaleón a la isla del patagón para luego regresar a Apolonia. Pues bien, en la costa sur del Mar Negro es donde se hallaba la región de la Paflagonia, podríamos decir frente a Apolonia, y la topografía de la Paflagonia coincide con la de la

117 Primaleón (guía de lectura), pp. 91-95.

118 Del griego 'Aло $\lambda \lambda \omega v i ́ \alpha$. Cuarenta y nueve lugares llamados Apollonia aparecen en Emilio Loria, Salute e magia attraverso $i$ secoli, Piccin, Padova, 1994, pp. 163-165.

119 Pontus Euxinos, como fue denominado el actual Mar Negro.

120 Loria, op. cit., p. 164.

121 Observamos que en el Diccionario del mundo clásico sólo aparecen cuatro sitios llamados Apollonia (p. 119) al igual que en Heinrich KiePERT, A manual of ancient geography, Macmillan, London, 1881, p. 203, de las cuales sólo dos se refieren a la misma Apollonia, razón por la que pensamos que éstas dos han sido las de mayor relevancia o presencia histórica. Una corresponde a la Apollonia Magna y la otra a Apollonia en Illyria, actual Albania, pero a ésta la descartamos porque se encontraba a $20 \mathrm{kms}$ de la costa Adriática y Primaleón parte embarcado desde Apolonia. De aquí en adelante, cada vez que nombremos Apolonia, estaremos haciendo referencia a Apollonia Magna. 
isla del patagón, ambas tienen una zona costera y una zona interior montañosa.

\section{LA ÉPICA TROYANA EN LAS NOVELAS DE CABALLERÍAS Y LA PAFLAGONiA}

$\mathrm{Al}$ decir de Ingela Nilsson: "Troy legends have come down to us in different forms, basically belonging to three genres: epic, history, and novel/romance [lo resaltado es nuestro]"122, expresando también que: "poetic licence allowed authors to express non-Homeric Troy matter in a Homeric style, or Homeric legends on vernacular verse, or to mix material taken from different sources" (pp. 11-12). Incluida en la tradición clásica ${ }^{123}$, la épica troyana ha formado parte en diferentes momentos de las novelas de caballerías, comenzando en Francia para fines del siglo XII y en España a partir de fines del siglo Xv. "El tema de Troya... -es, sin lugar a dudas, el ciclo mítico más prestigioso y fecundo- ofrece su argumento a una serie de crónicas que se escalonan a lo largo de los siglos XIV y Xv [en España]"124. Lida de Malkiel ha expresado: "En ningún momento de la Edad Media las personas de alguna cultura dejaron de conocer la leyenda de Troya"125.

Ahora bien, la Paflagonia, o mejor dicho los paflagones, formaron parte de la guerra de Troya incluyéndolos Homero en su Ilíada $a^{126}$ y, por otro lado, podemos ver en el Primaleón cómo se recuerdan las guerras troyanas en el último capítulo en un poema dirigido al lector:

Aquí la excelencia de tulio exmaltada / vence y excede a los libros hispanos / las guerras de Troya de Grecia y romanos/ debuxa con pluma de sciencia dorada: / aquí Palmerino corona su espada

122 "From Homer to Hermoniakos: Some considerations of Troy matter in Byzantine literature", Troianalexandrina, 4 (2004), p. 12.

123 María Rosa Lida de Malkiel, La tradición clásica en España, Ariel, Barcelona, 1975.

124 Vicente Cristóbal, "Mitología clásica en la literatura española: consideraciones generales y bibliografía”, Cuadernos de Filología Clásica. Estudios Latinos, 18 (2000), p. 35.

125 La tradición clásica, p. 365.

126 Homeri, Opera, Scriptorum Classicorum Bibliotheca Oxonensis, Iliadis libros I-XII, continens, editio tertia, tomvs I, Londini, OXONII [1952], Canto 2.851, 5.577, 13.656, 13.661. 
/ las cosas del fijo gran Primaleón / demuestra inuencibles con mucha razón / y vuelve las otras vencibles en nada (cap. 217, f. xii [ccxxiv] $v$, lo resaltado es nuestro).

Elementos comunes entre patagón, Paflagón y Paflagonia

Veamos nuevamente:

- El instrumento que llevaba colgado el patagón del Primaleón era de viento como el instrumento musical llamado "paflagonia".

- El instrumento llamado "paflagonia" es "antiguo".

- Es verosímil pensar que el nombre del instrumento de viento "paflagonia" esté relacionado con la región de la Paflagonia.

- La región de la Paflagonia se encontraba sobre el Mar Negro, al sudeste de Apolonia y al este de Constantinopla, geografía por la que se trasladaba el Primaleón.

- La región de la Paflagonia estuvo bajo el dominio griego, "concentró la vida comercial en la costa, en la que los griegos fundaron factorías"127.

- El colofón del Primaleón especifica: "Fue trasladado este segundo libro de Palmerín llamado Primaleón... de griego en nuestro lenguaje castellano y corregido y enmendado" (cap. 217, f. xii [ccxxiv]v).

_ "Fueron los paflagonios un pueblo grosero ${ }^{128} \ldots$ Entre los griegos era insulto llamarle á uno paflagonio"129. Esto nos recuerda lo dicho por Marín Pina: "Los patagones descubiertos por Primaleón no son sino una tribu de salvajes" (p. 433) y lo observado por Enrique Pato "que ansí las llamamos nosotros por salvajes [a las patagonas]" (p. 3).

- El patagón del Primaleón vive en un isla donde "la mayor población que ella tiene es enla co / sta dela mar y a vna parte desta ysla ay muy gran / des montañas" (cap. 133, f. xxix [cxxxiii]r). La Paflagonia no es una isla, pero le corresponde un extenso litoral marítimo y una zona interior montañosa: "el

127 Diccionario enciclopédico hispano-americano de literatura, ciencias, artes, etc., Montaner y Simón-W.M.Jackson, New York-Barcelona, 1939, t. 15, p. 566.

128 Tosco, bruto, ordinario, primitivo.

129 Diccionario enciclopédico hispano-americano, p. 566. 
litoral era fértil... mientras que el país alto era montañoso y con bosques" $" 130$.

\section{Posibles orígenes del nOMbre PATAGÓN EN el PrIMALEÓN}

Presentamos las siguientes hipótesis para responder a los posibles orígenes del nombre patagón en el Primaleón:

a) Original escrito en griego

Sabemos que fue práctica habitual en los libros de caballerías utilizar como recurso literario la falsa traducción, es decir, adjudicar la autoría del mismo a otro autor en alguna lengua exótica. Continuando con este pensamiento es coherente pensar que el autor del Primaleón haya utilizado este mismo recurso o tópico cuando expresa en su colofón, como ya hemos visto: "fue trasladado... de griego a nuestro lenguaje castellano". Ahora bien, observando lo dicho por Marín Pina en su guía de lectura del Primaleón:

La autoría de ambas obras [Palmerín de Oliva y el Primaleón] es incierta y, de creer la información recogida en el colofón del Primaleón, fueron los dos traducidos del griego al castellano por un vecino de Ciudad Rodrigo llamado Francisco Vázquez, miembro de una reconocida familia mirobrigense pero, hasta la fecha, sin ninguna vinculación documental con las obras ${ }^{131}$.

Observado esto y si aceptamos la posibilidad de que haya existido un original escrito en griego del Primaleón nos preguntamos: ¿en lugar de patagón no habrá estado escrito paphlagón?, de ser así: ¿cómo pudo haber pasado la "phl” de paphlagón a la "t" de patagón?

Analizando las formas en las cuales pudo haber estado escrito en griego paphlagón para poder derivar en patagón, observamos que posiblemente el traductor pudo haber confundido el símbolo de la letra $p h i$, un óvalo con un trazo vertical: $\Phi$ (mayúscula) de ПАФААГОN о $\varphi$ (minúscula) de $\pi \alpha \varphi \lambda \alpha \gamma o v$, por el símbolo de la letra theta, un óvalo con un trazo horizontal: $\Theta$ (mayúscula) de ПА $\Theta \Lambda$ АГОN o $\theta$ (minúscula) de $\pi \alpha \theta \lambda \alpha \gamma o v$. En este caso, se leería como pazlagon, sonido muy similar a pata-

130 Diccionario del mundo clásico, p. 1238.

131 Primaleón (guía de lectura), p. 7 (lo resaltado es nuestro). 
gon, pero en el Primaleón está escrito patagon y no pazlagon. Observamos la similitud entre la lambda mayúscula $\Lambda$ y la alpha mayúscula A de ПА $\Theta \Lambda$ АГON yevaluamos la posible fusión de estas letras. El profesor Cavallero nos confirmó que en mayúscula la theta y phi se confunden mutuamente ${ }^{132}$ al igual que la lambda y alpha ${ }^{133}$, expresándonos:

el proceso pudo darse a partir de un texto en mayúscula donde: paphlagón > pathlagón > pathaagón > pathagón > patagón. Es

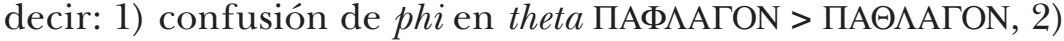
confusión de lambda en alpha (duplicación de alpha) ПАӨААГОN, 3) simplificación de la alpha ПАЄАГОN y 4) pérdida de la espiración de la theta y paso a taû ПАТАГОN. Sea porque los copistas consideraron un error de duplicación de alpha o sea porque ellos mismos se confundieron, las dos alphas pudieron simplificarse. La pérdida de la espiración es normal en español (comunicación personal, mayo de 2007).

b) Original en castellano pero escrito "paflagón" en lugar de "patagón" Consideramos también la existencia de un original desconocido escrito en castellano donde haya podido encontrarse escrito paflagón en lugar de patagón. En este caso observamos que el brazo o barra de la letra "f" bien pudo haberse alterado ${ }^{134}$ durante la copia por un empaste de cuño y unirse a la siguiente "l" formando una doble "tt" unidas por un solo brazo: paflagon > pattagon, quizás pudo haberse trastocado ${ }^{135}$ la " $\mathrm{f}$ " por " $\mathrm{t}$ " y empastado el cuño o leído simplemente por error " $\mathrm{t} t$ "136.

132 Filippo Ronconi, La traslitterazione dei testi greci, una ricerca tra paleografia e filologia, Fondazione Centro Italiano di Studi sull'Alto Medioevo, Spoleto, 2003, pp. 90 y 98.

133 Ibid., pp. 84 y 91 .

134 Observamos entre las probables alteraciones de una obra las producidas por un "molde deshecho accidentalmente, con posible empastelado en algunos casos" (Jaime Moll, "Problemas bibliográficos del libro del Siglo de Oro", BRAE, 59, 1979, p. 70).

$135 \mathrm{Al}$ respecto observamos algunos ejemplos de variantes de estado que nos presenta Germán Orduna al comparar dos ejemplares de la primera edición del Belianís de Grecia: "trastocar $l$ por $b$ y $u$ por $l$, y cambiar $d$ por $g$, crea un nuevo vocablo... 'oluidados'... 'obligados'... cambiar y trastocar tipos que, a veces, logra palabras distintas. Así cambiar em por an, crea... 'temblando les'... 'tan blando les'... cambiar i por o, crea... 'priuar'... 'prouar' [etc.]” (Ecdótica problemática de la edición de textos, Reichenberger, Kassel, 2000, p. 119).

136 Alberto Blecua expresa: "En el caso de la copia al dictado... en la lectura pueden confundirse una letras por otras -un grafema por otro- 
paflagon > patlagon > pattagon, o trastocada la "l" por "t": paflagon > paftagon > pattagon, o simplemente haberse leído mal y confundir " $\mathrm{fl}$ " por " $\mathrm{tt}$ ", luego en cualquiera de estos casos muy fácilmente puede haber pasado a una sola " $t$ ": pattagon > patagon.

c) "Patagón" escrito premeditadamente en lugar de "paflagón"

Por último, pensamos que no deberíamos descartar la posibilidad de que el autor del Primaleón haya, premeditadamente, querido escribir patagón en lugar de paphlagón o paflagón, usando quizás el mismo recurso utilizado por el autor del Amadís de Gaula, que vinculara al Amadís con la inexistente región de Gaula $^{137}$ probablemente recordando a la sí existente región de Gales [Wales] ${ }^{138}$ o a la Galia $^{139}$ o la presencia del rey Artús en lugar del rey Arturo en el Tirant lo Blanc o en el Quijote de la Mancha.

\section{Conclusión}

Teniendo en cuenta las hipótesis antedichas, pensamos que es posible que el autor del Primaleón, al hacer viajar al héroe Primaleón en un entorno cercano a Constantinopla, entre geografías conocidas, ignotas o imaginarias, haya tenido en cuenta la existente región de la Paflagonia, habitada por groseros, toscos y mal vistos por los griegos paflagones, para desarrollar las aventuras del Primaleón en la innominada isla donde hiciera habitar al salvaje patagón. También pensamos que es probable que exista una relación entre el cuerno que llevaba colgado el patagón del Primaleón y el instrumento de viento llamado paflagonia.

de acuerdo con las semejanzas gráficas" (Manual de crítica textual, Castalia, Madrid, 1983, p. 18).

137 Cabe observar que Edwin B. Place, "Amadis of Gaul, Wales, or what?", $H R, 23$ (1955), p. 10, analiza la posibilidad de que el autor realmente haya querido escribir Gaula recordando lo escrito en el Amadis: "aquel reyno de Gaula no nos faltará en la pequeña Bretaña”.

138 "Perión, rey de Gaula (esto es, del país de Gales)" (Marcelino Menéndez y Pelayo, Orígenes de la novela, Emecé, Buenos Aires, 1945, p. 348).

139 Edwin Place (op. cit., p. 101) citando a Miss. Williams expresa: "in the beginning Gaula is undoubtedly France or a part of it”. 
Dicho esto, nos permitimos exponer estas ideas para su discusión y en un futuro quizás probar que el topónimo Patagonia, en su origen, no haya sido sólo un nombre de fantasía "desprovisto de toda etimología" ${ }^{40}$.

Miguel Armando Doura

Universidad Católica Argentina

140 Morales, op. cit., p. 17. 